\title{
Microstructural understanding of the oxidation of an austenitic stainless steel in high-temperature steam through advanced characterization
}

Zhao Shen ${ }^{1 *}$, David Tweddle ${ }^{1}$, Hongbing $\mathrm{Yu}^{2}$, Guanze $\mathrm{He}^{1}$, Aakash Varambhia ${ }^{1}$, Phani Karamched ${ }^{1}$, Felix Hofmann ${ }^{2}$, Angus J. Wilkinson ${ }^{1}$, Michael P. Moody ${ }^{1}$, Lefu Zhang ${ }^{3}$, Sergio Lozano-Perez ${ }^{1}$

${ }^{1}$ Department of Materials, University of Oxford, Parks Road, OX1 3PH Oxford, UK

${ }^{2}$ Department of Engineering Science, University of Oxford, Parks Road, OX1 3PJ Oxford, UK

${ }^{3}$ School of Nuclear Science and Engineering, Shanghai Jiao Tong University, 800 Dongchuan Road, 200240 Shanghai, China

*Corresponding author

zhao.shen@materials.ox.ac.uk 


\begin{abstract}
It is well-known that steels always oxidize faster in the environments containing water vapour than in dry oxygen. Due to the difficulties in obtaining necessary experimental scale of observations, the mechanisms responsible for the steam-accelerated oxidation are still unclear. Through a combination of multiscale characterization techniques, the surface oxide film formed on an Fe-17Cr-9Ni stainless steel after exposure to high-temperature steam has been studied in detail. The characterization results obtained in this study reveal that the formation of the inner oxide layer, which is critical in protecting the base metal, is due to internal oxidation instead of external oxidation. The classic internal oxidation model underestimates the thickness of the inner oxide layer by one order of magnitude. This difference can be explained by the existence of fast diffusion channels in the inner oxide layer. This study provides direct evidence of a high density of nanopores in the oxide phase of the internal oxide layer, which can act as fast-diffusion channels if interconnected, and proposes their mechanisms of formation, a consequence of water dissociation-induced protons promoting the formation, migration, and clustering of both cation and anion vacancies.
\end{abstract}

Key words: Stainless steel; Internal oxidation; Nanoporous; Transmission electron microscopy; Atom probe tomography.

\title{
1. Introduction
}

For many decades, due to their low cost, good mechanical properties, and high corrosion resistance in high-temperature environments, high $\mathrm{Cr}$ ferritic-martensitic (F-M) steels, typically ranging from 9 to 12 weight percentage of $\mathrm{Cr}$, have been widely used as heat-resisting materials in the energy generating systems, in which water is used as heat-transfer medium [1-5]. To achieve greater thermal efficiencies and reduce emissions, the advanced energy generating systems, such as supercritical water reactors and ultra-supercritical fossil fuel power-generating units, are designed to operate at ever higher temperatures $\left(>600^{\circ} \mathrm{C}\right)$. However, in service of temperatures above $600^{\circ} \mathrm{C}$, the high $\mathrm{Cr} \mathrm{F}-\mathrm{M}$ steels are reported to suffer severe corrosion issues [6-12]. Thickening and failure of surface oxides are of increasing concern in a variety of energy production plants. For example, the progressive reduction of heat transfer by thickening oxides can lead to over-heating and failure, and exfoliation of these oxides can result in blocking of tubes or, if the oxide fragments are transported in the steam, erosion of the steam turbine [2]. Despite the high-temperature corrosion of F-M steels has been extensively studied [1-18], effective remedy solutions have not be developed, especially in the environments containing water vapour, which significantly limits the application of the F-M steels in the high-temperature aqueous environments.

Compared with the F-M steels, the Fe-Cr-Ni stainless steels exhibit much better corrosion resistance in the high-temperature aqueous environments $[2,7,11,15,16,19,20]$. Hence, the Fe-Cr-Ni stainless steels are selected to replace these high Cr F-M steels [2]. Similar to the enhanced corrosion of F-M steels in the environments containing vapour [21-27], the steam-accelerated corrosion is also observed in the Fe-Cr-Ni stainless steels [28, 29]. In the study of F-M steels in high-temperature steam, several mechanisms have been proposed to explain the steam-accelerated corrosion [21-27]. Among these mechanisms, the formation of volatile Cr-oxyhydroxides decreasing scale compactness [22] and accumulation of growth stress leading to scale cracking [25] have attracted most attentions. Compared with the F-M steels, the mechanisms controlling the steam-accelerated oxidation of Fe-Cr-Ni stainless steels have received less attention in the literature [28-30], although there are significant similarities between the two. In order to better understand the steam-accelerated corrosion in Fe-Cr-Ni stainless steels, a comprehensive high-resolution approach is needed. 
According to the results reported in the literature [31-37], a dual-layered surface oxide film, consisting of a Fe-rich outer oxide layer and a Cr-rich inner oxide layer, will form on Fe-Cr-Ni stainless steels after exposure to high-temperature steam. The outer oxide layer is generally believed to grow by outward Fe cation diffusion through the inner and outer oxide layers to the outer oxide layer-steam interface, while the inner oxide layer grows by inward oxygen diffusion through the inner and outer oxide layers to the metal matrix-inner oxide layer interface. In the study of F-M steels exposed to hightemperature water vapour, it was previously proposed that oxygen penetrates the inner oxide layer incorporated in water molecules since an accumulation of $\mathrm{H}$ was found around the oxidation front [38]. However, the size of water molecule is too big to diffuse through the lattice of $\mathrm{Cr}$-rich spinel. As a result, the existence of fast-diffusion channels in the inner oxide layer was proposed by a number of researchers [38-41]. In some of these studies, the existence of cavities in the inner oxide layer, acting as fast-diffusion channels, has been reported [8-10, 42, 43]. Was et al. [32] also proposed the existence of fast-diffusion channels in the inner oxide layer of 304 and 316 stainless steels in the hightemperature steam. However, it should be pointed out that, due to the difficulties in obtaining the necessary experimental scale of observations (micro-to-atomic), there is no convincing experimental evidence to support this hypothesis yet. This work hopes to make a relevant contribution in this respect, as it will be shown in the next sections. The existence of nanoporosity (or not) is essential to understand the mechanisms controlling the oxide growth.

Recent developments in high-resolution microscopy techniques, enabling a more detailed characterization of material microstructure, have significantly advanced our understanding of a range of previously unresolved phenomena [44-49]. In this study, we use a combination of microscale Secondary Electron Microscopy (SEM), Energy Dispersive X-ray (EDX), and Electron Back Scattered Diffraction (EBSD), nanoscale on-axis Transmission Kikuchi Diffraction (TKD), Transmission Electron Microscopy (TEM), and Electron Energy Loss Spectroscopy (EELS), and atomic-scale Atom Probe Tomography (APT) and High-Angle Annular Dark Field (HAADF) imaging to conduct a direct study on the oxide formed on a Fe-17Cr-9Ni stainless steel after exposure to low-oxygen hightemperature steam.

\section{Materials and methods}

The Fe-17Cr-9Ni stainless steel used in this study was provided by Bao-Steel Corporation and tested in solution annealed condition. The chemical composition is $16.91 \mathrm{Cr}, 8.87 \mathrm{Ni}, 0.082 \mathrm{C}, 0.001 \mathrm{~S}, 0.18$ $\mathrm{Si}, 0.022 \mathrm{P}, 0.41 \mathrm{Cu}, 0.049 \mathrm{~V}$, and balance $\mathrm{Fe}$ (wt. \%). The average grain size is around $40 \mu \mathrm{m}$.

The coupons used for corrosion test were machined from a plate to dimensions of $15 \mathrm{~mm} \times 30 \mathrm{~mm} \times 2$ $\mathrm{mm}$, followed by grinding with emery paper up to 2000 grit. Then the coupons were subsequently cleaned with acetone and rinsed with de-ionized water in ultrasonic cleaner. The corrosion test was carried out in a circulating autoclave system with a $1.5 \mathrm{~L}$ autoclave made of Ni-based alloy 625 , a water chemistry controlling unit, and a temperature controller, as shown schematically in Fig. 1. The coupons were exposed to steam for $1500 \mathrm{~h}$ at a temperature of $600{ }^{\circ} \mathrm{C}$ under a pressure of $25 \mathrm{MPa}$. The circulating flow rate was controlled at about $3 \mathrm{~L} / \mathrm{h}$ by high pressure metering pump combined with a high precision back pressure regulator, which provided about 2 times of volumetric refresh rates of pure de-ionized water in the autoclave. Dissolved oxygen (DO) concentration at autoclave inlet was controlled below $10 \mathrm{ppb}$ by continuous bubbling of high purity argon gas in the water tank. Outlet water from the autoclave was purified by the nuclear grade mixed resin bed and the conductivity in the water storage tank was kept at about $0.056 \mu \mathrm{S} / \mathrm{cm}$. DO at the autoclave inlet and conductivity at autoclave inlet and outlet were monitored continuously by on-line meters. 
The morphology of the cross-section of the surface oxide film was examined by SEM using a Field Emission Gun (FEG) Zeiss Crossbeam 540 equipped with Oxford Instruments X-max 150 EDX detector and NordlysMax 3 EBSD detector systems. Chemical composition of the surface oxide film was examined by low-energy EDX at a working distance of $5.2 \mathrm{~mm}$, a beam voltage of $5 \mathrm{kV}$ and a 2 nA probe current. A lower accelerating voltage $(5 \mathrm{kV}$ vs. $20 \mathrm{kV})$ increased both the spatial resolution and signal-to-noise ratio. More details can be found in [50]. To examine the crystallographic orientation of the surface oxide film, EBSD maps were obtained at a working distance of $18 \mathrm{~mm}$ and a sample tilt of $70^{\circ}$, with a beam voltage of $20 \mathrm{kV}$ and $15 \mathrm{nA}$ probe current.

The site-specific TEM samples were prepared by Focused Ion Beam (FIB). A single beam FEI FIB200 equipped with a static micromanipulator was used for trenching and in-situ lift-out. A dual beam Zeiss NVision 40 FIB-SEM was subsequently used for thinning sample to a thickness less than $50 \mathrm{~nm}$. Since FIB milling could introduce significant damage on the sample surface, final low energy cleaning $(5 \mathrm{kV}$, $250 \mathrm{pA}$ ) with FIB was performed on both sides of the thin foil after a conventional milling to minimize the damage.

TKD analysis was performed on the TEM samples using a Zeiss Merlin FEG-SEM equipped with a Bruker Optimus TKD Detector head that allows for better spatial resolution with minimal sample drift. The sample was held normal to the electron beam at a working distance of $5 \mathrm{~mm}$ and Kikuchi patterns captured underneath with a horizontal phosphor screen at an accelerating voltage of $20 \mathrm{kV}$ and a probe current of $1.5 \mathrm{nA}$. The step sizes were set to $3-10 \mathrm{~nm}$. The data was subsequently post-processed by Channel 5 software to obtain Image quality, misorientation (MO), and inverse pole figure (IPF) maps.

TEM analysis was performed with a JEOL 2100 (operating voltage $200 \mathrm{kV}$ ) for imaging and Selected Area Electron Diffraction (SAED). High-resolution analysis, including HAADF and EELS, was conducted with a JEOL ARM200F (cold-field emission gun) operating at $200 \mathrm{kV}$ and equipped with a Gatan Quantum spectrometer. The annular angular range used for HAADF imaging was 73-236 mrad. EELS spectra (low- and core-loss) were acquired correcting the spatial drift and recalibrated in energy using the zero loss peak as a reference. Principal components analysis (for denoising) was performed using Hyperspy 1.1 (open source) software. The convergence and collection half-angles were 31 and $41 \mathrm{mrad}$, respectively. EELS quantification was performed in Digital Micrograph by the background subtraction method. The relatively low thickness of all areas analyzed $(\sim 40 \mathrm{~nm})$ allow for a reliable quantification without removing plural scattering. This was checked for regions of known composition (e.g. matrix).

APT samples were prepared by FIB, using a dual beam Zeiss NVision 40 FIB-SEM. Samples were trenched and lifted out and attached to individual posts on a silicon coupon. FIB was then used to mill the sample into a sharp needle, with an approximate tip radius of $50 \mathrm{~nm}$. Finally, a low energy cleaning step $(2 \mathrm{kV}, 300 \mathrm{pA})$ was applied to the needle to minimize surface damage. APT analysis was performed using a LEAP $5000 \mathrm{XR}$, with a detection efficiency of 52\%. Samples were analysed using a laser energy (UV - $355 \mathrm{~nm}$ laser) of $50 \mathrm{pJ}$, sample temperature of $50 \mathrm{~K}$, a pulse frequency of $125 \mathrm{kHz}$ and a detection rate of $0.3 \%$. The APT data was processed using IVAS 3.8.2, with the needle shape estimated using a voltage reconstruction.

\section{Results}

\subsection{Microscale characterization of the surface oxide film}

As shown in Fig. 2a, the surface oxide film formed on Fe-17Cr-9Ni stainless steel after exposure to high-temperature steam for $1500 \mathrm{~h}$ has a duplex structure: an outer Fe-rich oxide layer $(\sim 50 \mu \mathrm{m})$ and 
an inner Cr-rich inner oxide layer $(\sim 60 \mu \mathrm{m})$, which corresponds well to the results in the literature [2, $7,16,19,31-37]$. In addition, the results in the literature [21] suggest that the outer-inner oxide layers interface coincides with the original specimen surface, similarly to what was observed in this sample. EDX line-scan was also conducted to reveal the qualitative (net counts) and quantitative (atomic ratio) distribution of chemical composition across the surface oxide film, as shown in Fig. 2b. The qualitative line-scan shows that there is a significant loss of Fe in the inner oxide layer. This part of Fe is believed to be consumed by the outward diffusion towards the outer oxide layer-steam interface during exposure, forming the Fe-rich outer oxide layer [2, 7, 16, 19, 31-37]. Compared with the decline of Fe in the inner oxide layer, the contents of $\mathrm{Cr}$ and $\mathrm{Ni}$ are nearly the same with that in the metal matrix, although they have bigger fluctuations. The quantitative line-scan shows that the outer oxide layer appears to be composed of $\mathrm{Fe}_{3} \mathrm{O}_{4}$, while the chemical composition of the inner oxide layer is not compatible with any common phase, although it is usually reported to be Cr-rich spinel [2, 7, 16, 19, 31-37]. It is worth noting that there is a thin layer of oxide $(\sim 10 \mu \mathrm{m}$ in thickness) just beneath the outer-inner oxide layers interface, where the fluctuations of the chemical composition were much bigger than in the other part of the inner oxide layer. The formation of this layer of oxide is attributed to the existence of a deformation layer introduced by the surface mechanical polishing. This hypothesis can be proved by the results reported in $[34,35]$, in which the mechanical polishing-induced deformation layer has been proved to change the oxidation processes locally due to the existent of high density of dislocations.

Figs. 3a and $\mathrm{b}$ show the SEM and Forward Scatter Detector (FSD) images of the cross-section of the surface oxide film, respectively. Micro-cavities were observed in the outer oxide layer. Similar results were also reported in [2, 7, 16, 19, 31-37]. EBSD analysis reveals that the outer oxide layer consists of randomly oriented columnar crystallites while the inner oxide layer retains the crystallographic information of the metal matrix (Fig. 3c). Similar results were also reported for 316 stainless steel, 304 stainless steel, and Alloy 690 after exposure to high-temperature steam, although a detailed explanation is missing [32, 33, 51].

\subsection{Nano-to-atomic scale characterization of the surface oxide film}

\subsubsection{TEM imaging and SAED analysis}

Recent studies [35, 48] show that the oxide grain boundaries may work as fast-diffusion channels. Considering the high grain boundary density in the outer oxide layer, it may have much lower protectiveness compared to the inner oxide layer since it retains the same crystallographic information with the original base metal and no new grain boundaries form. In addition, the columnar oxide grains in the outer oxide layer further shorten the diffusion path, resulting in a worse protectiveness. As a result, the inner oxide layer is the main focus of this research. To study the inner oxide layer in its entirety, two site-specific TEM samples were prepared from different depths. The positions of the two TEM samples relative to the original specimen surface are shown in Fig. 4.

Bright Field TEM (BFTEM) imaging and SAED analysis were conducted on the two thin TEM foils. As shown in Fig. 5a, the inner oxide layer appears to be composed of two phases: a bright phase (phase 1) and a dark phase (phase 2). The SAED pattern taken at Region A reveals that it has the same austenitic phase as the metal matrix (Fig. 5b). The SAED pattern taken at Region B exhibits double diffraction with the two phases contributing being austenite and a chromite-type spinel oxide (Fig. 5c). To reveal the crystallographic orientation relationship between the inner oxide layer and the metal matrix, SAED was conducted at the interface within Region $\mathrm{C}$, which consists of half metal matrix and half inner oxide layer (Fig. 5a). The diffraction pattern obtained from the metal matrix is coherent with the diffraction pattern obtained from the inner oxide layer (Fig. 5d). This suggests that the 
austenite phase in the inner oxide layer has the same crystallographic structure and orientation as the metal matrix. In addition, the two phases in the inner oxide layer have an epitaxial orientation relationship along the [001] direction. The orientation relationship between the two phases can be described as $[002]_{\mathrm{M}} / /[004]_{\mathrm{O}}$ and $(001)_{\mathrm{M}} / /(001)_{\mathrm{O}}$ (' $\mathrm{M}$ ' indicates metal phase and ' $\mathrm{O}$ ' indicates oxide phase).

\subsubsection{HAADF imaging and FFT analysis}

Fig. 6a shows a High Angle Annular Dark Field (HAADF) image of the two-phase structured inner oxide layer. Since HAADF is sensitive to the material atomic density (Z-contrast), the dark and bright phases correspond to the oxide and metallic austenite, respectively. Fig. $6 \mathrm{~b}$ shows an atomic-resolution HAADF image of the two-phase structure and the epitaxial orientation relationship between the two phases can also be observed. Fast Fourier Transform (FFT) patterns confirm that phase A is chromitetype spinel oxide that has grown coherently with the austenite metal phase B. However, their different lattice parameters lead to the formation of misfit dislocations (every 7 continuous planes in the metal phase take a dislocation to accommodate the misfit of the two phases, Fig. 6c). No other dislocations are observed in the metal surrounding the oxide phase. Since there is no significant difference between the two lattices, the interface between the two phases can be classified as a semi-coherent interface [52]. The exact formulation of the spinel oxide cannot be identified by only indexing the SAED or FFT patterns since this group of Fe-Cr spinels usually has very similar lattice parameters. To identify the formulation of the spinel oxide, a quantitative EELS chemical analysis was performed (shown in section 3.2.4).

\subsubsection{TKD analysis}

TKD was conducted on both TEM samples and the results support the coexistence of an austenite metal phase and a spinel oxide phase in the inner oxide layer (red and green represent austenite and spinel phases, respectively), as shown in Fig. 7a (TEM sample 1). Further observation reveals that the inner oxide layer contains similar volume fractions of metal and oxide phases. The two phases appear to exist as interpenetrating networks through the whole thickness of the inner oxide layer. In addition, due to the extended angular range covered by TKD, the epitaxial orientation relationship between the two phases observed in 2 dimensions (Figs. 5c and 6b) is further confirmed to exist in 3 dimensions (Fig. 3a). Compared with the SAED and atomic imaging, TKD analyses samples a larger region and provide orientation information in 3 dimensions. The results in Fig. 7a show that the metal phase in the inner oxide layer has the same crystallographic orientation as the metal matrix, which is consistent with the SAED results (Fig. 5d) and the EBSD results (Fig. 3e). TKD was also conducted on TEM sample 2 and the results are consistent with that obtained from TEM sample 1 (Fig. 7b).

\subsubsection{EELS analysis}

Fig. 8a shows the morphology of the inner oxide layer around the oxide-metal interface (TEM sample 1). Spherical-looking internal oxide precipitates are observed at the oxidation front. EELS valence analysis similar to [28] reveals that only $\mathrm{Cr}$ is initially oxidized in this precipitates, suggesting that chromia is forming. These chromia precipitates will turn to chromite with the increase of exposure time. More details about the morphology and chemical composition of the small oxide precipitates can be found in the supplementary materials (Fig. S1). With the increase in oxidation time, the sizes of the discrete oxide precipitates start to grow up until forming an interconnected two-phase structure. Figs. $8 \mathrm{~b}$ and $\mathrm{c}$ show the EELS signal intensity maps and line-scan. Compared with the unaffected metal matrix, the metal phase in the inner oxide layer contains a higher net content of $\mathrm{Fe}$ and $\mathrm{Ni}$ and lower 
content of Cr, while the oxide phase shows an opposite trend. Since the EDX line-scan (Fig. 2b) shows that the net contents of $\mathrm{Cr}$ and $\mathrm{Ni}$ in the inner oxide layer are nearly the same with the unaffected metal matrix, the different contents of $\mathrm{Cr}$ and $\mathrm{Ni}$ in the two phases are supposed to be caused by locally redistribution through short range diffusion or expulsion. Although the net content of Fe in the inner oxide layer is lower than in the unaffected metal matrix (due to the outward diffusion and formation of the outer oxide layer, Fig. 2b), the austenite metal phase has higher net content of Fe than the unaffected metal matrix, suggesting that a part of Fe in the region now occupied by oxide phase has been expelled into the metal phase during the oxidation process (Fig. 8c). Expulsion of Ni from the oxide phase into the austenite metal phase is also observed (Fig. 8c). Fig. 8d shows the quantitative distribution of chemical composition in the two phases in the region just behind the oxidation front. The metal phase is mainly composed of $\mathrm{Fe}$ and $\mathrm{Ni}$. $\mathrm{Cr}$ is also observed in the metal phase, while the concentration of $\mathrm{Cr}$ is not uniform, ranging from 0 to $8 \%$ at. The oxide phase consists of $\mathrm{O}, \mathrm{Cr}$, and $\mathrm{Fe}$, and no $\mathrm{Ni}$ is observed in this phase. Combining the results obtained from Figs. 5 and 6 and the elemental atomic ratio obtained from Fig. 8d, the oxide phase can be formulated as $\mathrm{FeCr}_{2} \mathrm{O}_{4}$.

Since the chemical composition in the inner oxide layer is nearly uniform (excluding the mechanicalpolishing affected layer, Fig. 2b), another TEM sample was prepared from the middle region of the inner oxide layer for a better representation (Fig. 4). A two-phase structure is also observed in TEM sample 2 (Fig. 9a), which is very similar to TEM sample 1. EELS signal intensity maps and line-scan show that the metal phase is composed of $\mathrm{Ni}$ and $\mathrm{Fe}$, and the oxide phase consists of $\mathrm{O}, \mathrm{Fe}$, and $\mathrm{Cr}$, as shown in Figs. $9 \mathrm{~b}$ and c. The chemical composition in the metal phase is much more uniform than that observed in TEM sample 1, suggesting that the local redistribution of $\mathrm{Cr}$ and $\mathrm{Ni}$ might have reached a balanced state. In addition, there is nearly no $\mathrm{Cr}$ (within statistical error) in the metal phase observed in TEM sample 2, suggesting that all $\mathrm{Cr}$ has been consumed in forming the oxide phase. An EELS quantitative line-scan was also conducted, as shown in Fig. 9d. Together with the TKD results, the oxide phase can also be formulated as $\mathrm{FeCr}_{2} \mathrm{O}_{4}$.

\subsubsection{APT analysis}

As shown in Figs. 8d and 9d, we can always observe $\sim 10 \%$ at. of oxygen in the metal phase. We assumed that the detected oxygen in the metal phase might be due to surface oxidation of the TEM foils during and/or after the sample preparation. To confirm this hypothesis, APT was conducted. The APT needles were prepared from the region around $20 \mu \mathrm{m}$ away from the original specimen surface, as shown in Fig. 4. Fig. 10a shows the spatial separation of the two phases in the inner oxide layer $(\mathrm{Cr}$ in red and $\mathrm{Ni}$ in green). The spatial distributions of $\mathrm{O}, \mathrm{Cr}, \mathrm{Fe}$, and $\mathrm{Ni}$ are separately shown in Fig. $10 \mathrm{~b}$. The results are consistent with the results obtained from EELS. A plane with thickness of $\sim 5 \mathrm{~nm}$ is extracted from the dataset and a quantitative line-scan across the interface of the two phases is acquired, as shown in Fig. 10c. Since the line-scan is extracted from the interior of the APT needle, the effect of surface oxidation can be eliminated. According to the atomic ratio obtained from the line-scan, the oxide phase can be formulated as $\mathrm{FeCr}_{2} \mathrm{O}_{4}$, which corresponds to the results obtained from EELS. In addition, nearly no oxygen (within statistical error) is observed in the metal phase, indicating that the oxygen observed in EELS is mainly due to surface oxidation during and/or after sample preparation.

\subsubsection{Oxide nanoporosity}

Since HAADF imaging is very sensitive to the atomic variations (including atomic number, density and thickness), it can be used to identify porosity within a single phase structure. Fig. 11a shows the typical morphology of the inner oxide layer in TEM sample 2. The signal intensity within the oxide 
phase is not uniform, with many randomly distributed black spots, suggesting that it is porous. Compared with the oxide phase, the signal intensity in the metal phase is much more uniform, indicating a compact structure. To further confirm that the black spots in the oxide phase are pores/voids, EELS mapping was conducted. The EELS quantitative maps show that the concentrations of $\mathrm{O}, \mathrm{Cr}$, and $\mathrm{Fe}$ are uniform (Fig. 11b), while the EELS qualitative maps show that the net counts of $\mathrm{O}, \mathrm{Cr}$, and $\mathrm{Fe}$ are all lower at the black spots (Fig. 11c). These results imply the existence of nanopores in the oxide phase. The diameter of the nanopores is $3 \pm 2 \mathrm{~nm}$, which is larger than a water molecule $(\sim 0.28 \mathrm{~nm})$. A similar nanoporous structure of the oxide phase is also observed in TEM sample 1, as shown in Fig. 8a. The presence of pores/voids can also be inferred in Fig 6a from the changes in signal intensity (lower when density/thickness is lower), with lower intensity regions of similar sizes to those in Fig 11a.

\section{Discussion}

\subsection{Current understanding of the oxidation mechanism}

The oxidation of Fe-Cr-Ni stainless steels in high-temperature aqueous environment has been extensively studied in the past decades. Although a double-layered surface oxide film has been widely reported, the inner oxide layer has been believed to be fully oxidized and acts as a continuous oxide layer [2, 15, 53-55]. However, in the current study, due to the application of high-quality microscopy, more details have been observed. Among these findings, the co-existence of oxide phase and metal phase inside the base metal and the existence of small oxide particles at the oxidation front are the typical features of internal oxidation [56-62]. The occurrence of internal oxidation has traditionally been associated with the diffusion of oxygen into the metal ahead of the oxidation front being the rate controlling process [56-62].

The model proposed by Carl Wagner [56] has been widely used in the study of internal oxidation due to the well agreement between the experimental measured oxidation rate and calculated rate based on this model. The model assumes that the content of oxygen is low and only less-noble elements can be oxidized [56, 57]. Therefore, once the concentration of less-noble element is lower than a critical value, only internal oxidation can occur and the external oxide layer is absent. However, in most practical applications of susceptible alloys at high temperatures, the internal oxide zone is formed below an external oxide scale [57], which is similar to the case observed in the present study. As a result, the oxidation observed in this study can be described as a combination of external oxidation and internal oxidation. Analytical solutions for the kinetics of internal oxidation in combination with an external scaling have been constructed and reviewed by Rapp [57]. In the following study conducted by Gesmundo et al. [63], the critical concentration of the less-noble component B required for the transition from internal to external oxidation in a binary A-B alloy for the case of simultaneous formation of an outer $\mathrm{AO}$ oxide has been proved to increase. If the same theory is adopted from Gesmundo et al. [63], the simultaneous formation of an $\mathrm{Fe}_{3} \mathrm{O}_{4}$ external layer may also increase the critical concentration of $\mathrm{Cr}$ required for the transition of internal oxidation to external oxidation.

Although only one specimen after exposure for $1500 \mathrm{~h}$ was analysed in this study, internal oxidation has been confirmed to be responsible for the formation of the inner oxide layer. According to the results observed in the present study and reported in the literature [57,63], a detailed description of the oxidation is proposed in Fig. 12. The high-resolution microscopy presented above proves that both $\mathrm{Cr}$ and $\mathrm{Fe}$ can be oxidized while Ni remains in metallic state under the testing environment. In our proposed model, when the Fe-17Cr-9Ni stainless steel coupon is exposed to the testing environment (Fig. 12a), an outer $\mathrm{Fe}_{3} \mathrm{O}_{4}$ oxide layer forms on the original specimen surface through external 
oxidation (outward diffusion of $\mathrm{Fe}^{+2 /+3}$ ). At the same time, inward diffusion of oxygen through austenite lattice will lead to the formation of $\mathrm{Cr}_{2} \mathrm{O}_{3}$ precipitates initially. The local supply of $\mathrm{Cr}$ is limited and these chromia precipitates will eventually be converted to $\mathrm{FeCr}_{2} \mathrm{O}_{4}$ (Fig. 12b). Since the outer oxide layer consists of small columnar oxide grains, both the outward diffusion of ionic Fe and inward diffusion of oxygen are still available through the high-density network of grain boundaries. After a longer exposure, the size of the internal oxide precipitates increases and new internal oxides precipitate deeper into the base metal (Fig. 12c). As exposure time increases, both the thicknesses of the outer and inner oxide layers increase, which will slow the transport of ionic Fe to the solution-outer oxide layer interface and oxygen to the inner oxide layer-metal matrix (Fig. 12d). As a result, the oxidation rate decreases with time.

It is worth noting that EBSD analysis shows that the inner oxide layer of the Fe-17Cr-9Ni stainless steel remains the same crystallographic information with the metal matrix (Fig. 3c). Similar phenomenon has also been reported by many other researchers [32, 33, 51]. Atomic-resolution imaging shows that although two phases (chromite and metal) exist in the inner oxide layer, these two phases all have a face-centred cubic structure and the lattice parameters of these two phases are very similar (Fig. 6). In addition, since the formation of the inner oxide layer has been proved to be due to internal oxidation, which follows a solid-state growth mechanism, the chromite and surrounding austenite is epitaxial. The great similarities between these two phases cannot be differentiated by EBSD analysis. This explains why the inner oxide layer remains the same crystallographic information with the unoxidized metal matrix under the EBSD analysis.

\subsection{Quantification of the nano-porosity in the inner oxide layer}

The results presented above confirm that the inner oxide layer is formed through internal oxidation, consisting of two interpenetrating networks of $\mathrm{FeCr}_{2} \mathrm{O}_{4}$ (chromite) and metallic $\mathrm{Fe}-\mathrm{Ni}$ austenite. Segmentation on HAADF images and EELS O elemental maps was used to estimate the fractions of both phases in the inner oxide. It was found that $54 \pm 6 \%$ of the volume is occupied by chromite and $46 \pm 6 \%$ by austenite, with an average chromite cluster diameter of $48 \pm 14 \mathrm{~nm}$ (over 100 clusters measured along the direction parallel to the oxide-metal interface). The $\mathrm{Ni}$ is pushed out of the growing chromite into the new austenite phase due to its lower oxygen affinity. When chromite starts forming, the number of $\mathrm{Fe}$ atoms per unit of volume in the neighbouring austenite is the same as it was in the matrix (there is no initial diffusion of Fe towards or away from the austenite). All Cr diffuses locally from the region that will become the $\mathrm{Fe}-\mathrm{Ni}$ austenite into the chromite. A fraction of the $\mathrm{Fe}$ in the region originally occupied by the matrix is oxidized to form the chromite and the rest diffuses out to form the external oxide. More specifically, if we consider a given volume in the inner oxide layer big enough to contain both austenite and chromite, as calculated from Fig. 2b, half of the original Fe atoms in the matrix diffuses outwards (long-range diffusion) as the inner oxide forms, with the remaining Fe distributed between the $\mathrm{FeCr}_{2} \mathrm{O}_{4}$ and the austenite. The $\mathrm{Cr}$ and $\mathrm{Ni}$ originally in the matrix only diffuse locally (short-range diffusion) to the $\mathrm{FeCr}_{2} \mathrm{O}_{4}$ and austenite, respectively. The results in Fig. 11 prove that the oxide phase in the inner oxide layer contains a high density of nanopores. Using the drop in HAADF signal intensity caused by the nanopores, the fraction of voids in the chromite phase is calculated to be $\sim 50 \%$ of its volume. In another words, $50 \%$ of the volume occupied by the chromite is empty. The average diameter of the voids is $3 \pm 2 \mathrm{~nm}$.

Compositional line profiles (Fig. $2 \mathrm{~b}$ ) reveal that $\sim 50 \%$ of the $\mathrm{Fe}$ atoms are missing in the inner oxide layer when compared to the same volume of matrix. However, this includes the austenite phase. When analysing the two phases separately, in the chromite phase, only $\sim 25 \%$ of the original Fe atoms remain 
while, initially, the austenite phase has the same number of $\mathrm{Fe}$ atoms per unit of volume as the matrix. If we only take into account the Pilling-Bedworth ratio of $\sim 2$ for the chromite, only $\sim 50 \%$ of the $\mathrm{Fe}$ atoms would need to diffuse out to explain this observation. However, only $25 \%$ remains in this phase, which is possible with $50 \%$ of the volume empty (voids). It is reasonable to assume that the outward diffusion of $\mathrm{Fe}$ atoms required to form the external oxide, together with the local diffusion of $\mathrm{Cr}$ and $\mathrm{Ni}$, has contributed to the high void density structure observed, that resembles those after selective dissolution or dealloying [64].

Although the oxide phase in the inner oxide layer has been proved to be nano-porous according to the results presented above, the formation mechanisms of the nano-cavities in the oxide phase is still unclear just based on the results in the present study. However, in a recent study [44], nano-pores were also observed in the oxide formed on an austenitic alloy exposed to steam at $350^{\circ} \mathrm{C}$, while the nanopores were not observed when the same alloy was exposed to dry oxygen at $350^{\circ} \mathrm{C}$. The formation mechanisms of the nano-pores were suggested to be due to the water dissociation-induced protons promoting the formation, migration, and clustering of both cation and anion vacancies. Considering the similarities between the results observed in the present study and in [44], the theory proposed in [44] can also be used to explain the formation of nano-porosities in the oxide phase of the inner oxide layer in the present study.

\subsection{Identification of the fast-diffusion channels in the inner oxide layer}

To protect the materials from further oxidation under the high-temperature environments, it is critical to form a continuous and protective oxide scale on the surface $[4,5]$. Although the surface scale formed on the Fe-17Cr-9Ni stainless steel appears to be continuous after a microscale characterization (Figs. 2 and 3), the nano-to-atomic scale observations presented in this study have clearly shown that the formation of the inner oxide layer is due to internal oxidation instead of external oxidation (Figs. 510). Hence, the inner oxide layer should be treated as an internal oxide layer. If these oxides were defect-free and, therefore, acted as an effective barrier for oxygen diffusion, the existence of an interconnected metal phase in the inner oxide layer would facilitate the inward diffusion of oxygen (as accepted for classical internal oxidation). In this study, due to the budget limit, the Fe-17Cr-9Ni stainless steel has not been tested without steam for comparison. However, the work conducted by Essuman et al. [26] has clearly shown that the existence of water vapour can significantly increase the tendency of Fe-Cr steels to be internally oxidized compared with exposure to dry oxygen, resulting in a much faster oxidation rate. As a result, it is sensible to postulate that the steam-accelerated oxidation of Fe-Cr-Ni stainless steels might be partially attributed to the enhanced internal oxidation compared with that in the environments without water vapour.

According to the classic internal oxidation model proposed by Carl Wagner [56], the thickness of the internal oxide layer can be roughly calculated as follow:

$$
X=\left[\frac{2 N_{O}^{(S)} D_{O}}{v N_{B}^{(O)}} t\right]^{1 / 2}
$$

where $\mathrm{X}$ is the thickness of the internal oxide layer; $N_{O}^{(S)}$ is the atomic fraction of dissolved oxygen at metal surface; $D_{O}$ is the diffusivity of oxygen in the base metal; $N_{B}^{(O)}$ is the atomic fraction of solute metal in bulk alloy; $\mathrm{v}$ is the number of oxygen ions per $\mathrm{B}$ ion in solute metal oxide $\mathrm{BO}_{\mathrm{v}}$. Since the internal oxide in the present study is $\mathrm{FeCr}_{2} \mathrm{O}_{4}, \mathrm{v}$ is calculated to be 4/3. Since all $\mathrm{Cr}$ and a part of $\mathrm{Fe}$ have been oxidized in the internal oxide layer, $N_{B}^{(O)}$ can be calculated as 1.5 times of $\mathrm{Cr}$ atomic 
percentage in the base metal, which is 0.27 . Values of $N_{O}^{(S)}$ and $D_{O}$ can be obtained from the literature [65], which are $1.39 \times 10^{-6}$ and $4.54 \times 10^{-10} \mathrm{~cm}^{2} / \mathrm{sec}$, respectively. As a result, the calculated thickness of the internal oxide layer is $1.37 \mu \mathrm{m}$, which is around one order of magnitude smaller than the measured thickness $(\sim 60 \mu \mathrm{m})$. This discrepancy between the calculated and measured thicknesses suggests that there must be some fast-diffusion channels that accelerate the oxidation process or that the assumption that the inner oxides were an effective barrier of $\mathrm{O}$ diffusion was incorrect.

Compared with the Fe-Cr-Ni stainless steel, the oxidation of F-M steels in high-temperature aqueous environment has been more extensively studied. The inner oxide layer formed on F-M steels is reported to consist of equiaxed nano-grains, and the grain boundaries of these nano-grains have been proposed as fast-diffusion channels during oxidation $[2,66,67]$. In our study, as shown in Fig. 3c, the inner (or internal) oxide layer retains the grain morphology from the metal matrix (with average oxide grains of $\sim 40 \mu \mathrm{m}$ ) and, therefore, has a relatively low grain boundary density. No nano-grains are observed in the inner oxide layer. Interestingly, similar results (in the form of "big" oxide grains) were also observed by Was et al. [32] and other researchers [33, 51], although they still suggested that grain boundary diffusion may be responsible. We propose that an alternative fast-diffusion channel through the inner oxide should exist.

In the study of the internal oxide formed in $\mathrm{Ni}-\mathrm{Al}$ alloy $[39,68,69]$, the internal oxide-metal interface was previously reported to be incoherent. During the internal oxidation, the diffusion of oxygen along the incoherent interface was enhanced, leading to the formation of needle-shape or cone-shape internal oxides. As a result, the incoherent oxide-metal interface has been supposed to be the fast-diffusion channels [69]. However, in the current study, the internal oxides at the oxidation front were approximately spherical and no enhanced diffusion along the oxide-metal interface is observed (Fig. S1), indicating that the semi-coherent interfaces in the inner oxide layer are not preferred fast diffusion paths. This hypothesis can be further proved by the atomic structure of the oxide-metal interface. As shown in Fig. 6c, due to the minor difference of lattice parameter between the chromite and austenite, the misfit dislocation density at the interface between the epitaxial-oriented two phases is very low, which might not play a critical role in accelerating diffusion.

Although the internal oxide precipitates at the oxidation front appear to be disconnected (Fig. S1), their sizes are growing bigger with the further exposure, resulting in the formation of interconnected oxide networks through the whole thickness of the inner (or internal) oxide layer (Figs. 5-7). Due to the application of high-resolution characterization in the present study, the oxide phase in the inner oxide layer is revealed to be nanoporous. In addition, considering the high volume fraction of nanopores in the oxide phase $(\sim 50 \%)$, it is sensible to believe that a part of nanopores in the inner oxide layer are connected and can work as fast-diffusion paths. Since the diameter of the nano-pores is $3 \pm 2 \mathrm{~nm}$ (Fig. 11a), the interconnected nano-pores could allow the direct diffusion of water molecule from the environment into the oxidation front, resulting in an enhanced oxidation. Thus, although chromite is generally believed to be compact and protective, the observed nanopores could allow for further ingression of water molecules and enhanced outward diffusion of cations (due to the presence of water in the nanopores). The formation of high density of nanopores in the oxide phase is then believed to be responsible for the differences between the calculated and measured thicknesses of the internal oxide layer.

\section{Conclusions}


The surface oxide film formed on an Fe-17Cr-9Ni stainless steel after exposure to high-temperature steam at $600^{\circ} \mathrm{C}$ for $1500 \mathrm{~h}$ has been studied by multiscale characterization techniques. A typical duallayered surface oxide film is observed. Although the two layers of oxide film appear to be continuous after a microscale characterization, the comprehensive nano-to-atomic scale of characterization in this work clearly shows that the inner oxide layer actually consists of two phases: Fe-Ni austenite and $\mathrm{FeCr}_{2} \mathrm{O}_{4}$ oxide and that there is evidence of internal oxidation (discrete oxides) into the metal. This suggests that the formation and observed microstructure of the inner oxide layer is due to prior internal oxidation instead of external oxidation. Oxygen could diffuse through the interconnected austenite metal phase in the inner oxide layer or water molecules could diffuse through the high density of nanopores in the chromite phase of the inner oxide layer, likely to also be interconnected for most of its thickness. For these reasons, and similar to the F-M steels, the steam-accelerated corrosion of the Fe-17Cr-9Ni stainless steel is proposed to be due to the occurrence of internal oxidation in the environments containing water vapour.

The predicted thickness of the inner oxide layer is underestimated by around one order of magnitude if calculated based on the classic internal oxidation model. Fast diffusion through boundaries and interfaces is unlikely, due to the lack of nano-sized oxide grain boundaries and the semi-coherent nature of the oxide-metal phase boundaries in the inner oxide layer. The "non-protective" nature of the nanoporous oxide phase, which formed as a consequence of water dissociation-induced protons promoting the formation, migration, and clustering of both cation and anion vacancies, is a more plausible explanation for the observed corrosion rate.

\section{Acknowledgments}

The authors from Shanghai Jiao Tong University are grateful to the National Key Research and Development Program of China (YS2018YFE010246) for the financial support. The authors from University of Oxford would like to thank the EPSRC (EP/K040375/1, EP/N010868/1 and EP/R009392/1) grants for funding this research. Zhao Shen is grateful to China Scholarship Council (CSC) for providing PhD studentship.

\section{References}

[1] C. Cabet, F. Dalle, E. Gaganidze, J. Henry, H. Tanigawa, Ferritic-martensitic steels for fission and fusion applications. J. Nucl. Mater., 523(2019) 510-537.

[2] I.G. Wright, R.B. Dooley, A review of the oxidation behaviour of structural alloys in steam. Int. Mater. Rev., 55(2010) 129-167.

[3] S.R.J. Saunders, M. Monteiro, F. Rizzo, The oxidation behaviour of metals and alloys at high temperatures in atmospheres containing water vapour: A review. Prog. Mater. Sci., 53(2008) 775-837.

[4] N. Birks, G.H. Meier, F.S. Pettit, Introduction to the high temperature oxidation of metals. Cambridge University Press, 2006.

[5] D.J. Young, High temperature oxidation and corrosion of metals. Vol. 1., Elsevier, 2008.

[6] Y. Li, T. Xu, S. Wang, J. Yang, B. Fekete, J. Yang, A. Wu, J. Qiu, Y. Xu, D.D. Macdonald, Predictions and analyses on the growth behavior of oxide scales formed on ferritic-martensitic in supercritical water. Oxid. Met., 92(2019) 27-48.

[7] X. Guo, Y. Fan, W. Gao, R. Tang, K. Chen, Z. Shen, L. Zhang, Corrosion resistance of candidate cladding materials for supercritical water reactor. Ann. Nucl. Energy, 127(2019) 351-363. 
[8] L. Tan, X. Ren, T.R. Allen, Corrosion behavior of $9-12 \% \mathrm{Cr}$ ferritic-martensitic steels in supercritical water. Corros. Sci., 52(2010) 1520-1528.

[9] Y. Chen, K. Sridharan, T. Allen, Corrosion behavior of ferritic-martensitic steel T91 in supercritical water. Corros. Sci., 48(2006) 2843-2854.

[10] J. Bischoff, A.T. Motta, Oxidation behavior of ferritic-martensitic and ODS steels in supercritical water. J. Nucl. Mater., 424(2012) 261-276.

[11] I. Betova, M. Bojinov, P. Kinnunen, V. Lehtovuori, S. Peltonen, S. Penttilä, T. Saario, Composition, structure, and properties of corrosion layers on ferritic and austenitic steels in ultrasupercritical water. J. Electrochem. Soc., 153(2006) B464-B473.

[12] R. Viswanathan, J. Sarver, J.M. Tanzosh, Boiler materials for ultra-supercritical coal power plants—steamside oxidation. J. Mater. Eng. Perform., 15(2006) 255-274.

[13] F. Abe, Precipitate design for creep strengthening of 9\% Cr tempered martensitic steel for ultrasupercritical power plants. Sci. Technol. Adv. Mater., 9(2008) 013002.

[14] S.J. Zinkle, G.S. Was, Materials challenges in nuclear energy. Acta Mater., 61(2013) 735-758.

[15] G.S. Was, P. Ampornrat, G. Gupta, S. Teysseyre, E.A. West, T.R. Allen, K. Sridharan, L. Tan, Y. Chen, X. Ren, C. Pister, Corrosion and stress corrosion cracking in supercritical water. J. Nucl. Mater., 371(2007) 176-201.

[16] L. Zhang, Y. Bao, R. Tang, Selection and corrosion evaluation tests of candidate SCWR fuel cladding materials. Nucl. Eng. Des., 249(2012) 180-187.

[17] R. Viswanathan, J.F. Henry, J. Tanzosh, G. Stanko, J. Shingledecker, B. Vitalis, R. Purgert, US program on materials technology for ultra-supercritical coal power plants. J. Mater. Eng. Perform., 14(2005) 281-292.

[18] W.H. Yeo, A.T. Fry, J. Purbolaksono, S. Ramesh, J.I. Inayat-Hussain, H.L. Liew, M. Hamdi, Oxide scale growth and presumed exfoliation in a $700 \mathrm{C}$ or higher steam condition: A simulation study for future operations of ultra-supercritical power plants. J. Supercrit. Fluids, 92(2014) 215-222.

[19] X. Luo, R. Tang, C. Long, Z. Miao, Q. Peng, C. Li, Corrosion behavior of austenitic and ferritic steels in supercritical water. Nucl. Eng. Technol., 40(2008) 147-154.

[20] D. Gómez-Briceño, F. Blázquez, A. Sáez-Maderuelo, Oxidation of austenitic and ferritic/martensitic alloys in supercritical water. J. Supercrit. Fluid., 78(2013) 103-113.

[21] J. Bischoff, A.T. Motta, C. Eichfeld, R.J. Comstock, G. Cao, T.R. Allen. Corrosion of ferriticmartensitic steels in steam and supercritical water. J. Nucl. Mater., 441(2013) 604-611.

[22] J. Ehlers, D.J. Young, E.J. Smaardijk, A.K. Tyagi, H.J. Penkalla, L. Singheiser, W.J. Quadakkers, Enhanced oxidation of the $9 \% \mathrm{Cr}$ steel $\mathrm{P} 91$ in water vapour containing environments. Corros. Sci., 48(2006) 3428-3454.

[23] A. Rahmel, J. Tobolski, Einfluss von wasserdampf und kohlendioxyd auf die oxydation von eisen in sauerstoff bei hohen temperaturen. Corros. Sci., 5(1965) 333-346.

[24] A. Galerie, Y. Wouters, M. Caillet, The kinetic behaviour of metals in water vapour at high temperatures: Can General rules be proposed?. Mater. Sci. Forum, 369(2001) 231-238. 
[25] M. Schütze, D. Renusch, M. Schorr, Parameters determining the breakaway oxidation behaviour of ferritic martensitic 9\% $\mathrm{Cr}$ steels in environments containing H2O. Corros. Eng. Sci. Technol., 39(2004) 157-166.

[26] E. Essuman, G.H. Meier, J. Żurek, M. Hänsel, L. Singheiser, W.J. Quadakkers, Enhanced internal oxidation as trigger for breakaway oxidation of $\mathrm{Fe}-\mathrm{Cr}$ alloys in gases containing water vapor. Scripta Mater., 57(2007) 845-848.

[27] W.J. Quadakkers, J. Żurek, M. Hänsel, Effect of water vapor on high-temperature oxidation of FeCr alloys. JOM, 61(2009) 44-50.

[28] Z. Shen, D. Du, L. Zhang, S. Lozano-Perez, An insight into PWR primary water SCC mechanisms by comparing surface and crack oxidation. Corros. Sci., 148(2019) 213-227.

[29] A.N. Hansson, K. Pantleon, F.B. Grumsen, M.A. Somers, Microstructure evolution during steam oxidation of a $\mathrm{Nb}$ stabilized austenitic stainless steel. Oxid. Met., 73(2010) 289-309.

[30] J. Yuan, W. Wang, H. Zhang, L. Zhu, S. Zhu, F. Wang, Investigation into the failure mechanism of chromia scale thermally grown on an austenitic stainless steel in pure steam. Corros. Sci., 109(2016) $36-42$.

[31] M.F. Montemor, M.G.S. Ferreira, N.E. Hakiki, M.D.C. Belo, Chemical composition and electronic structure of the oxide films formed on 316L stainless steel and nickel based alloys in high temperature aqueous environments. Corros. Sci., 42(2000) 1635-1650.

[32] G.S. Was, S. Teysseyre, Z. Jiao. Corrosion of austenitic alloys in supercritical water. Corrosion, 62(2006) 989-1005.

[33] M. Nezakat, H. Akhiani, S. Penttilä, S.M. Sabet, J. Szpunar. Effect of thermo-mechanical processing on oxidation of austenitic stainless steel 316L in supercritical water. Corros. Sci., 94(2015), 197-206.

[34] S. Cissé, L. Laffont, B. Tanguy, M.C. Lafont, E. Andrieu, Effect of surface preparation on the corrosion of austenitic stainless steel 304L in high temperature steam and simulated PWR primary water. Corros. Sci., 56(2012) 209-216.

[35] J. Yuan, X. Wu, W. Wang, S. Zhu, F. Wang, The effect of surface finish on the scaling behavior of stainless steel in steam and supercritical water. Oxid. Met., 79(2013) 541-551.

[36] H. Asteman, J.E. Svensson, L.G. Johansson, Evidence for chromium evaporation influencing the oxidation of 304L: the effect of temperature and flow rate. Oxid. Met., 57(2002) 193-216.

[37] Y. Behnamian, A. Mostafaei, A. Kohandehghan, B. Zahiri, W. Zheng, D. Guzonas, M. Chmielus, W. Chen, J.L. Luo, Corrosion behavior of alloy 316L stainless steel after exposure to supercritical water at $500^{\circ} \mathrm{C}$ for $20,000 \mathrm{~h}$. J. Supercrit. Fluids, 127(2017) 191-199.

[38] L. Tomlinson, N.J. Cory, Hydrogen emission during the steam oxidation of ferritic steels: kinetics and mechanism. Corros. Sci., 29(1989) 939-965.

[39] S.R. Saunders, N.L. McCartney, Current understanding of steam oxidation-power plant and laboratory experience. Mater. Sci. Forum, 522(2006) 119-128. 
[40] N.J. Cory, T.M. Herrington, Kinetics of oxidation of ferrous alloys by super-heated steam. Oxid. Met., 28(1987) 237-258.

[41] G.B. Gibbs, R. Hales, The influence of metal lattice vacancies on the oxidation of high temperature materials. Corros. Sci., 17(1977) 487-507.

[42] L. Sun, W. Yan, Estimation of oxidation kinetics and oxide scale void position of ferriticmartensitic steels in supercritical water. Adv. Mater. Sci. Eng., 2017(2017) 9154934.

[43] L. Martinelli, C. Desgranges, F. Rouillard, K. Ginestar, M. Tabarant, K. Rousseau, Comparative oxidation behaviour of Fe-9Cr steel in $\mathrm{CO} 2$ and $\mathrm{H} 2 \mathrm{O}$ at $550 \mathrm{C}$ : Detailed analysis of the inner oxide layer. Corros. Sci., 100(2015) 253-266.

[44] L. Luo, M. Su, P. Yan, L. Zou, D.K. Schreiber, D.R. Baer, Z. Zhu, G. Zhou, Y. Wang, S.M. Bruemmer, Z. Xu, Atomic origins of water-vapour-promoted alloy oxidation. Nat. Mater., 17(2018) 514-518.

[45] A. Pratt, L. Lari, O. Hovorka, A. Shah, C. Woffinden, S.P. Tear, C. Binns, R. Kröger, Enhanced oxidation of nanoparticles through strain-mediated ionic transport. Nat. Mater., 13(2014) 26-30.

[46] D.G. Xie, Z.J. Wang, J. Sun, J. Li, E. Ma, Z.W. Shan, In situ study of the initiation of hydrogen bubbles at the aluminium metal/oxide interface. Nat. Mater., 14(2015) 899-903.

[47] A. King, G. Johnson, D. Engelberg, W. Ludwig, J. Marrow, Observations of intergranular stress corrosion cracking in a grain-mapped polycrystal. Science, 321(2008) 382-385.

[48] N. Mortazavi, C. Geers, M. Esmaily, V. Babic, M. Sattari, K. Lindgren, P. Malmberg, B. Jönsson, M. Halvarsson, J.E. Svensson, I. Panas, Interplay of water and reactive elements in oxidation of alumina-forming alloys. Nat. Mater., 17(2018) 610-617.

[49] T.L. Burnett, P.J. Withers, Completing the picture through correlative characterization. Nat. Mater., 18(2019) 1041-1049.

[50] M. Meisnar, S. Lozano-Perez, M. Moody, J. Holland, Low-energy EDX-A novel approach to study stress corrosion cracking in SUS304 stainless steel via scanning electron microscopy. Micron, 66(2014) 16-22.

[51] X. Guo, K. Chen, W. Gao, Z. Shen, P. Lai, L. Zhang. A research on the corrosion and stress corrosion cracking susceptibility of $316 \mathrm{~L}$ stainless steel exposed to supercritical water. Corros. Sci., 127(2017) 157-167.

[52] K. Kolluri, M.J. Demkowicz, Formation, migration, and clustering of delocalized vacancies and interstitials at a solid-state semicoherent interface. Phys. Rev. B, 85(2012) 205416.

[53] B. Stellwag, The mechanism of oxide film formation on austenitic stainless steels in high temperature water. Corros. Sci., 40(1998) 337-370.

[54] J. Robertson, The mechanism of high temperature aqueous corrosion of stainless steels. Corros. Sci., 32(1991) 443-465.

[55] D.D. Macdonald, The point defect model for the passive state. J. Electrochem. Soc., 139(1992) 3434-3449. 
[56] C. Wagner, Reaktionstypen bei der Oxydation von Legierungen. Z. Elektrochem., 63(1959), 772782.

[57] R.A. Rapp, Kinetics, Microstructures and mechanism of internal oxidation-its effect and prevention in high temperature alloy oxidation. Corrosion, 21(1965) 382-401.

[58] D.L. Douglass, A critique of internal oxidation in alloys during the post-Wagner era. Oxid. Met., 44(1995) 81-111.

[59] G.C. Wood, F.H. Stott, D.P. Whittle, Y. Shida, B.D. Bastow, The high-temperature internal oxidation and intergranular oxidation of nickel-chromium alloys. Corros. Sci., 23(1983) 9-25.

[60] F. H. Stott, G. C. Wood. Internal oxidation. Mater. Sci. Tech-Lond., 4(1988) 1072-1078.

[61] Y. Li, J.E. Morral, A local equilibrium model for internal oxidation. Acta Mater., 50(2002) 36833691 .

[62] S.W. Guan, W.W. Smeltzer, Oxygen solubility and a criterion for the transition from internal to external oxidation of ternary alloys. Oxid. Met., 42(1994) 375-391.

[63] F. Gesmundo, F. Viani, Transition from internal to external oxidation for binary alloys in the presence of an outer scale. Oxid. Met., 25(1986) 269-282.

[64] J. Erlebacher, M.J. Aziz, A. Karma, N. Dimitrov, K. Sieradzki, Evolution of nanoporosity in dealloying. Nature, 410(2001) 450-453.

[65] N. Otsuka, Y. Shida, H. Fujikawa, Internal-external transition for the oxidation of Fe-Cr-Ni austenitic stainless steels in steam. Oxid. Met., 32(1989) 13-45.

[66] L. Tan, Y. Yang, T.R. Allen, Oxidation behavior of iron-based alloy HCM12A exposed in supercritical water. Corros. Sci., 48(2006) 3123-3138.

[67] L. Tan, T.R. Allen, Y. Yang, Corrosion behavior of alloy $800 \mathrm{H}(\mathrm{Fe}-21 \mathrm{Cr}-32 \mathrm{Ni})$ in supercritical water. Corros. Sci., 53(2011) 703-711.

[68] D.P. Whittle, Y. Shida, G.C. Wood, F.H. Stott, B.D. Bastow, Enhanced diffusion of oxygen during internal oxidation of nickel-base alloys. Philos. Mag. A, 46(1982) 931-949.

[69] A. Martinez-Villafane, F.H. Stott, J.G. Chacon-Nava, G.C. Wood, Enhanced oxygen diffusion along internal oxide-metal matrix interfaces in $\mathrm{Ni}-\mathrm{Al}$ alloys during internal oxidation. Oxid. Met., 57(2002) 267-279. 


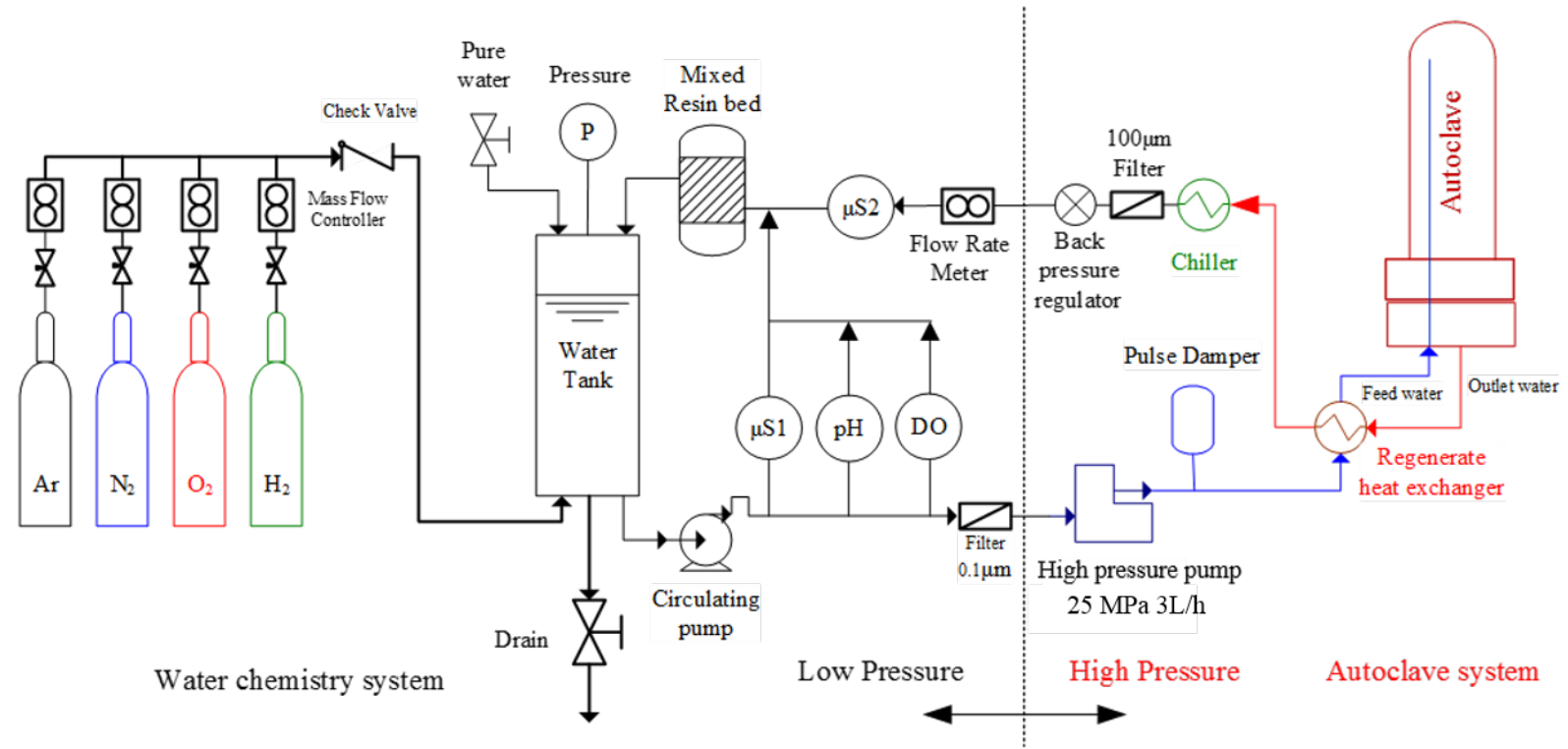

Fig. 1. Schematic of the high-temperature corrosion test system. 


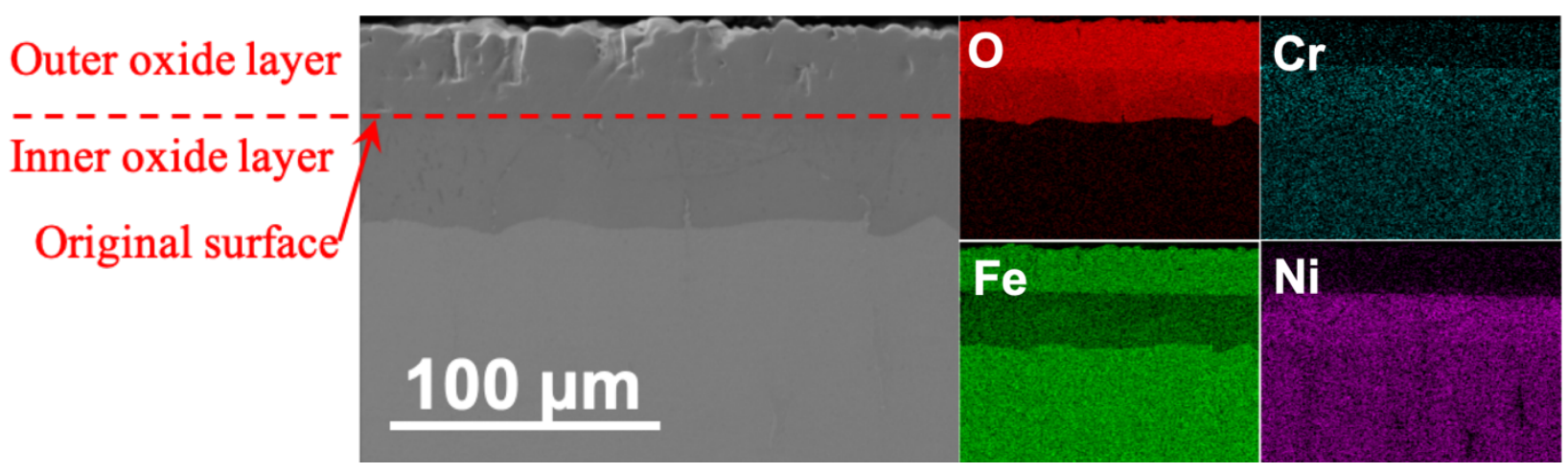

(a)

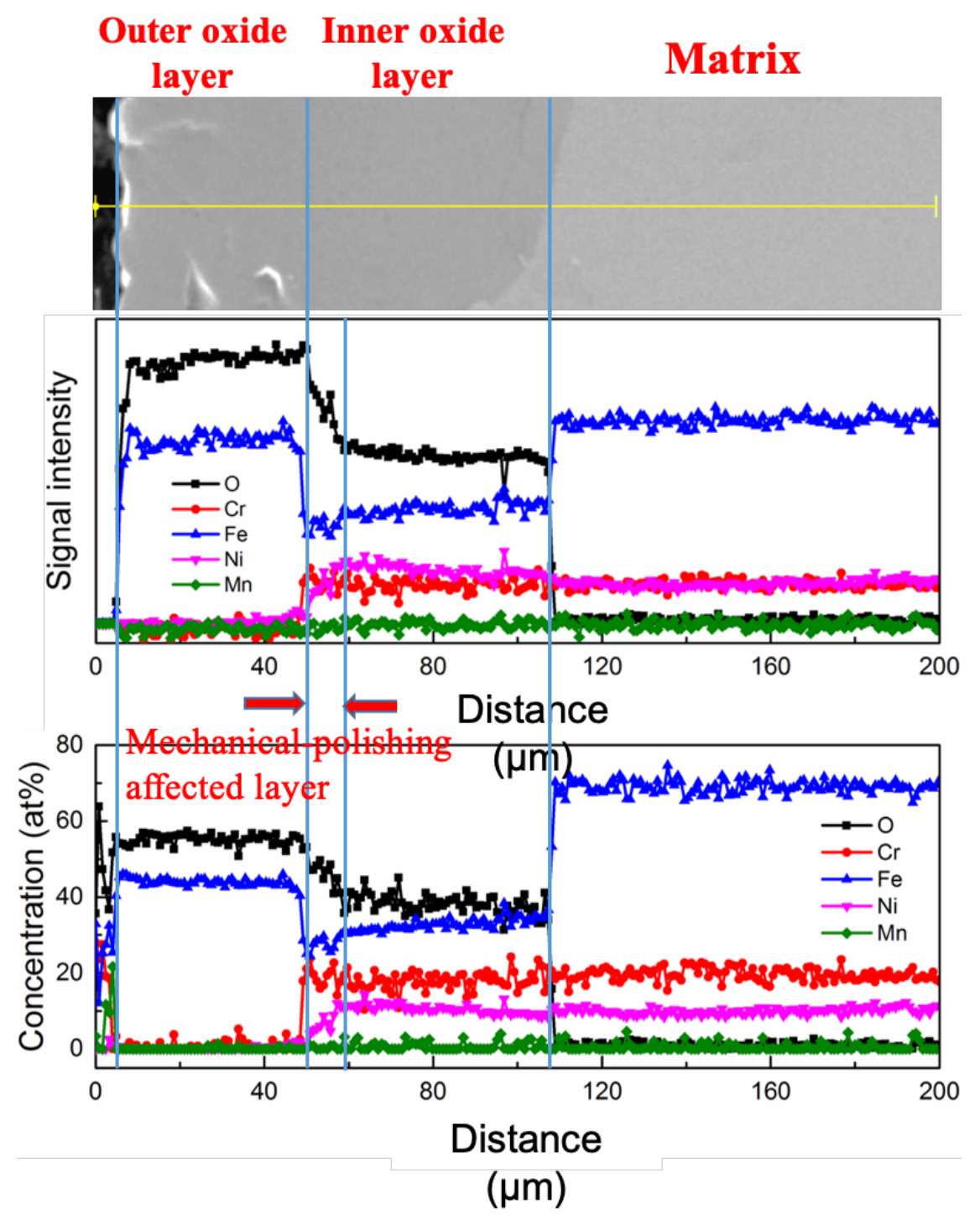

(b)

Fig. 2. (a) SEM-EDX elemental maps showing a double-layered surface oxide scale: a Fe-rich outer oxide layer and a Cr-rich inner oxide layer; (b) EDX line-scan showing the quantitative and qualitative distribution of chemical composition across the surface oxide film. 


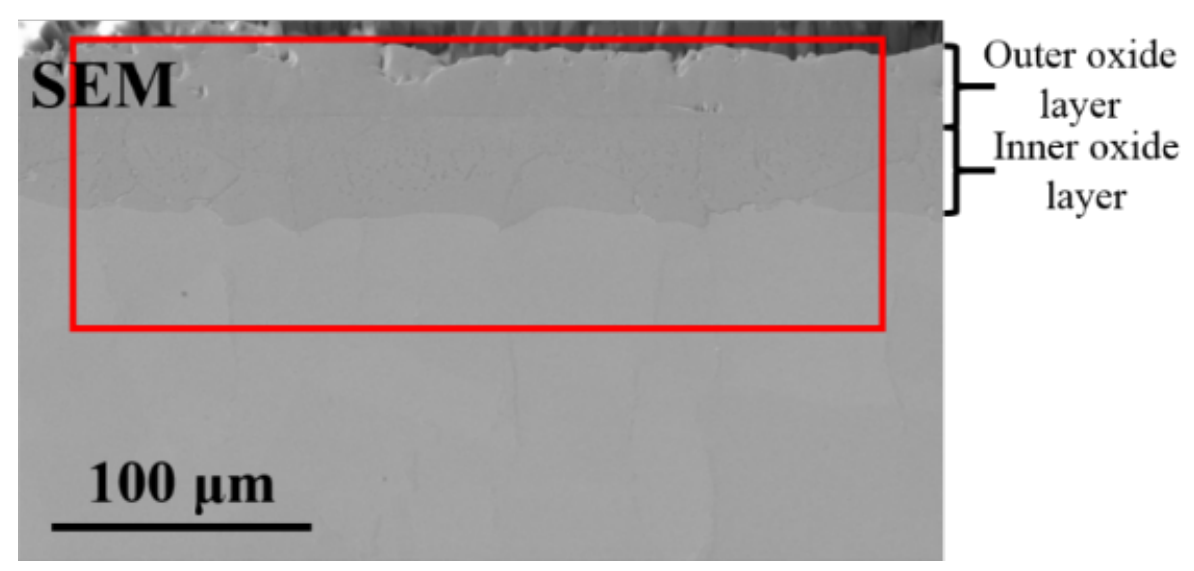

(a)

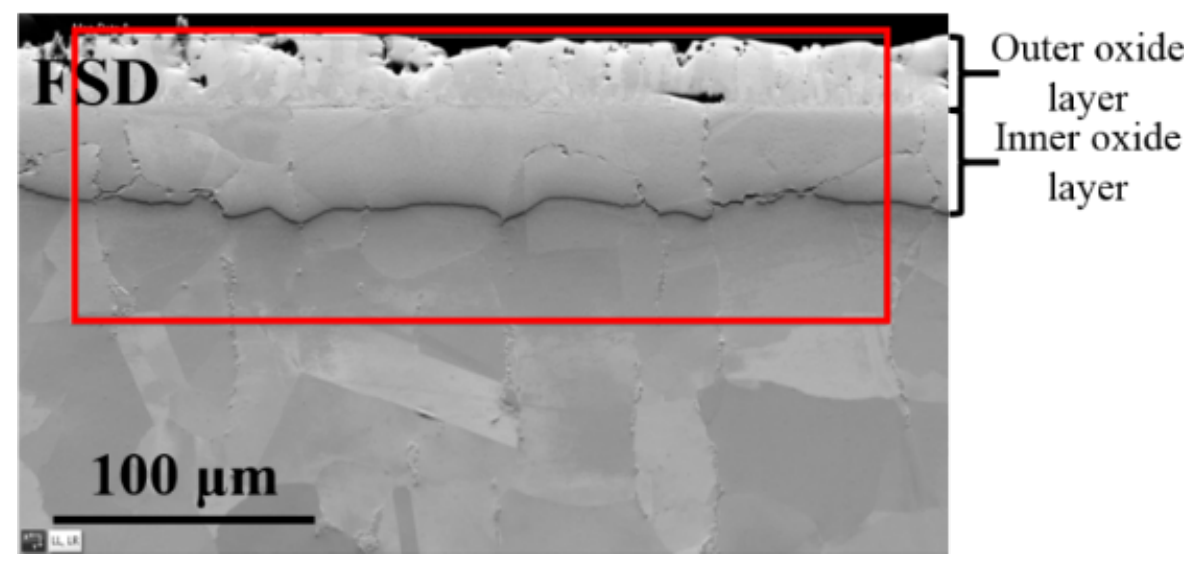

(b)

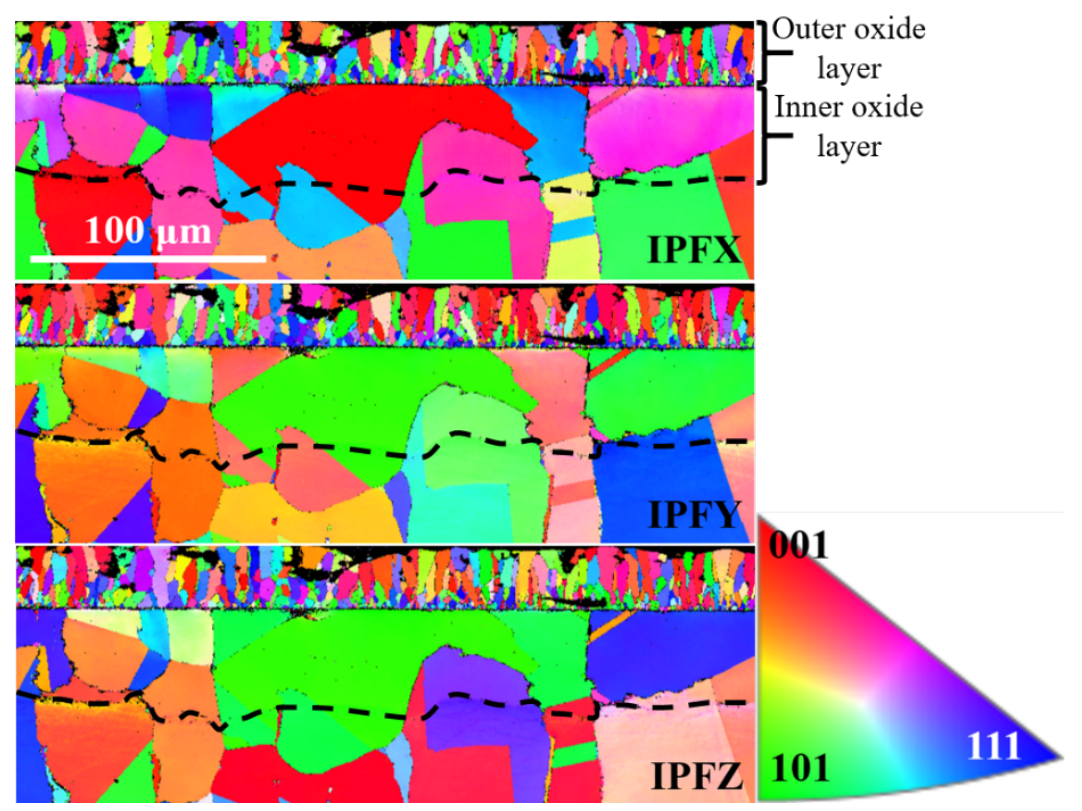

(c)

Fig. 3. (a) SEM image and (b) FSD image showing a double-layered structure of the surface oxide scale; (c) Inverse Pole Figure (IPF) maps revealing that the outer oxide layer consists of columnar grains and the inner oxide layer remains the same crystallographic orientation with the metal matrix (step size $=0.5 \mu \mathrm{m})$. 


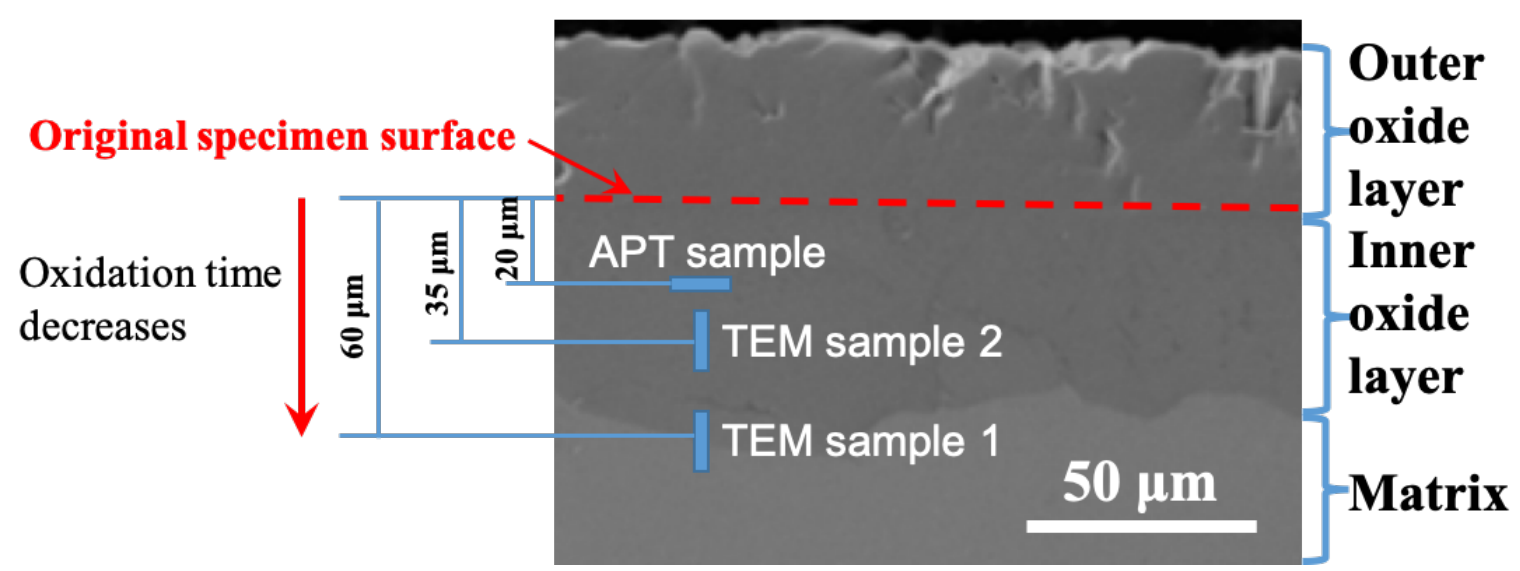

Fig. 4. Illustration of the positions of two TEM samples on the cross-section of surface oxide film. Two TEM samples were prepared from the regions around the inner oxide layer-metal matrix interface (TEM sample 1) and around the middle depth of inner oxide layer (TEM sample 2). APT samples were prepared from the region around $20 \mu \mathrm{m}$ away from the original specimen surface. 


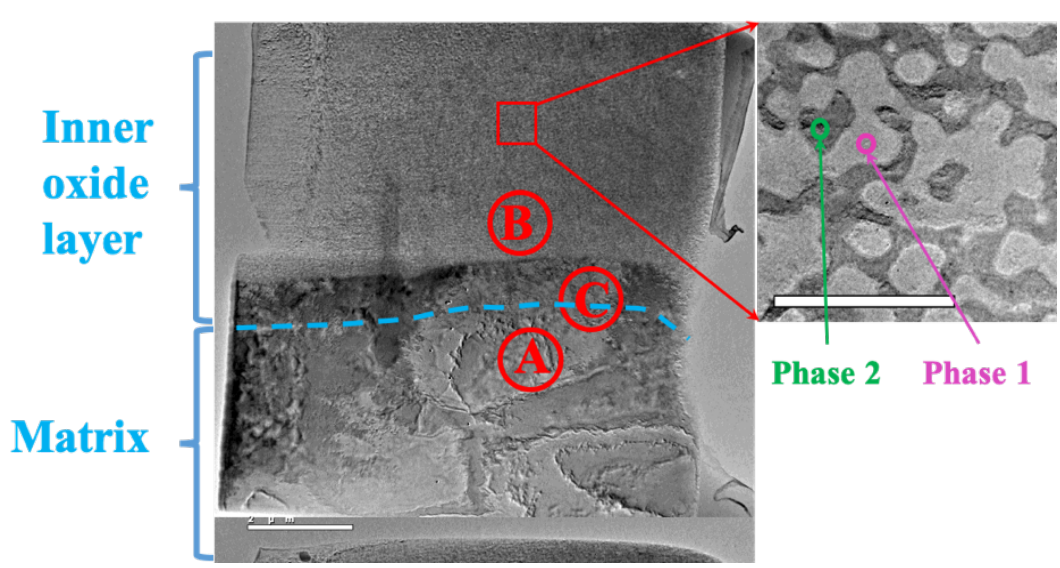

(a)

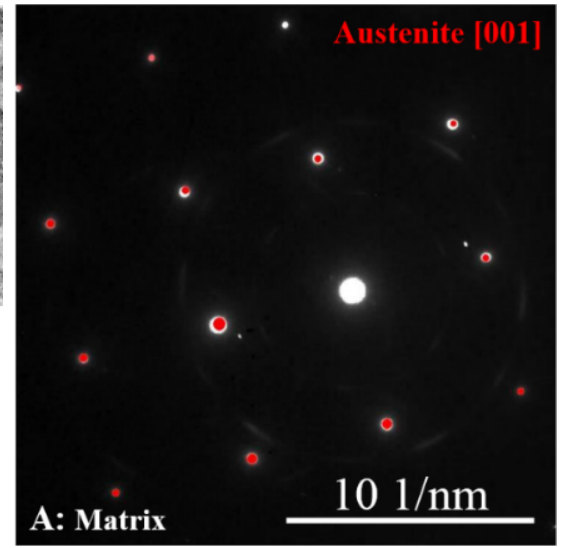

(b)

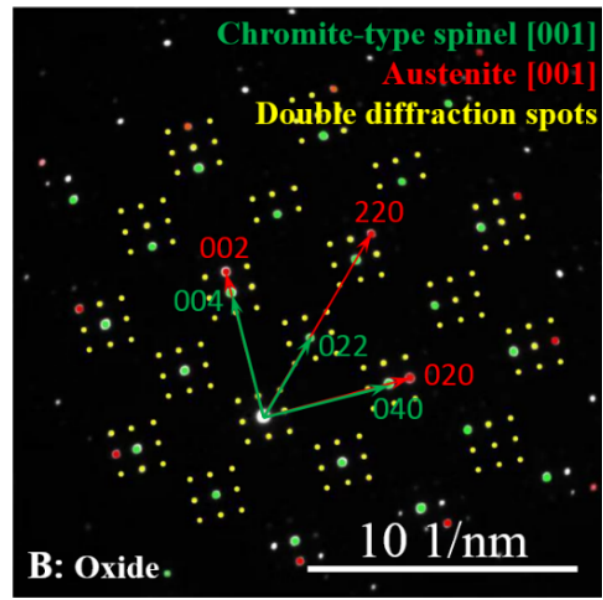

(c)

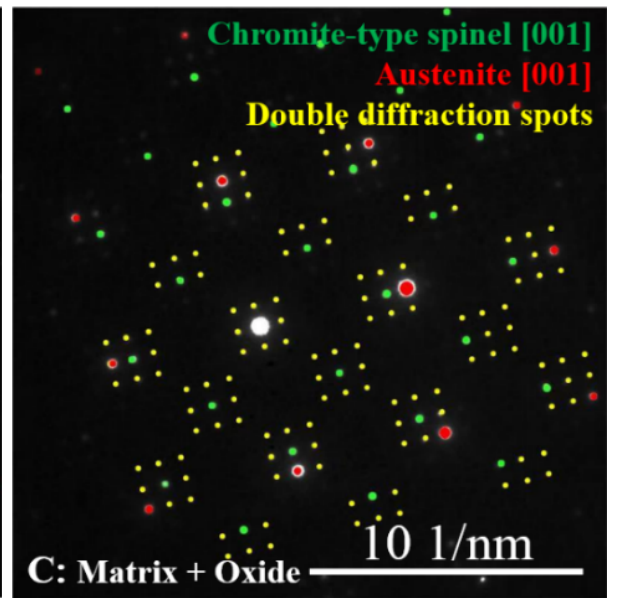

(d)

Fig. 5. (a) BFTEM image showing the TEM sample 1 prepared at the inner oxide layer-metal matrix interface and high-resolution BFTEM image showing that the inner oxide layer consists of two phases; (b) SAED pattern taken at Region A in (a) showing an austenite phase of the metal matrix; (c) SAED pattern taken at Region B in (a) showing the existence of double diffraction in the inner oxide layer; (d) SAED pattern taken at Region $\mathrm{C}$ in (a) showing that the SAED pattern obtained from the metal matrix is coherent with the SAED pattern obtained from the inner oxide layer. 


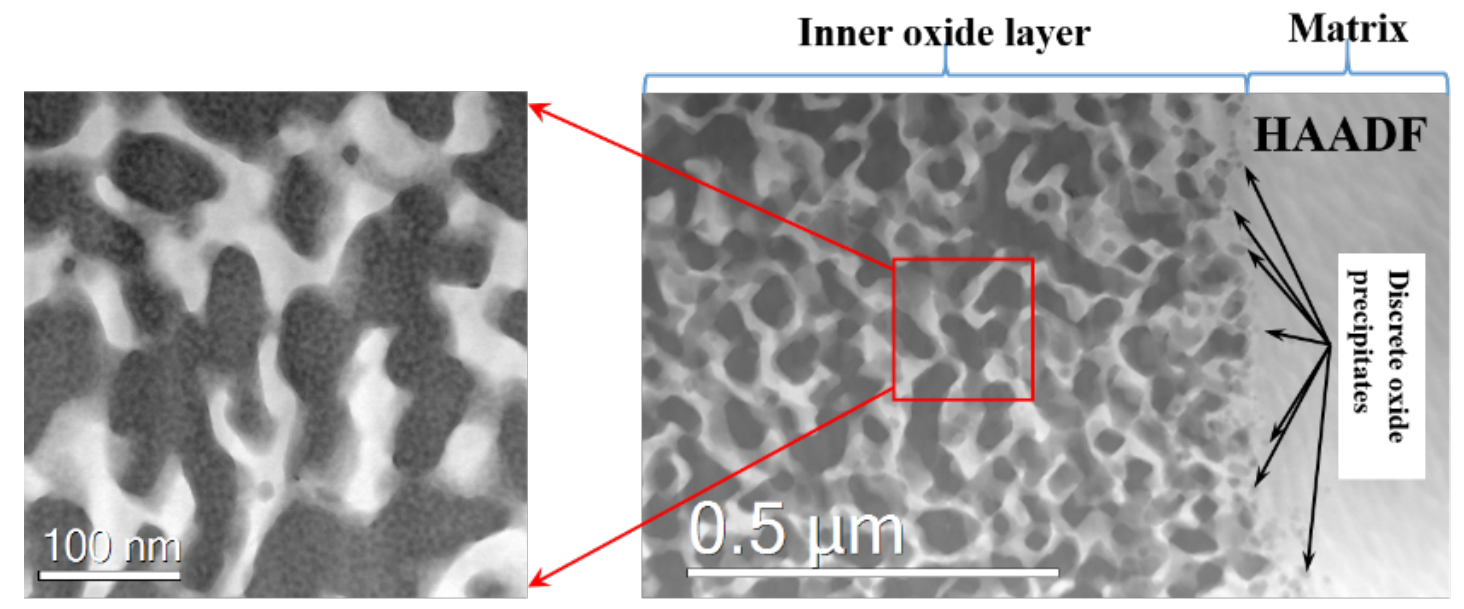

(a)

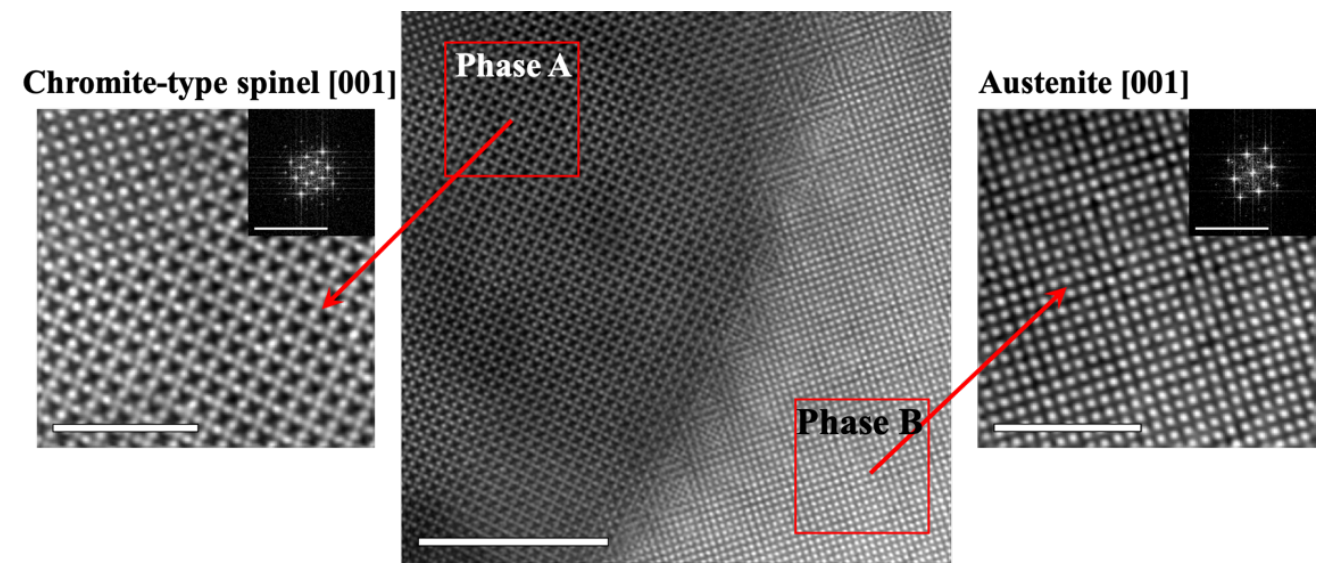

(b)

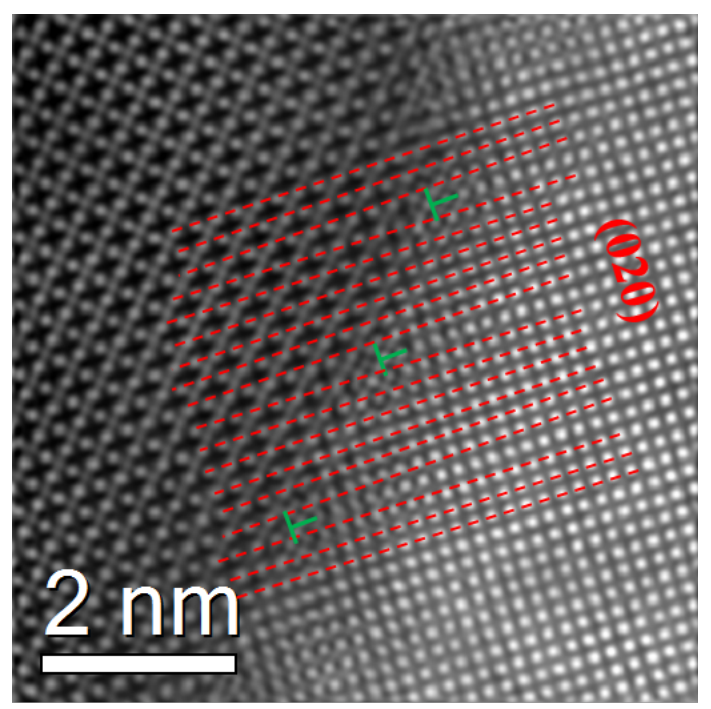

(c)

Fig. 6. (a) HAADF image showing a two-phase structure in the inner oxide layer (TEM sample 1); (b) atomic-resolution HAADF images showing that the inner oxide layer consists of chromite-type spinel and austenitic phases (TEM sample 1); (c) atomic-resolution HAADF image showing a semi-coherent interface between the oxide phase and the metal phase in the inner oxide layer (TEM sample 1). 


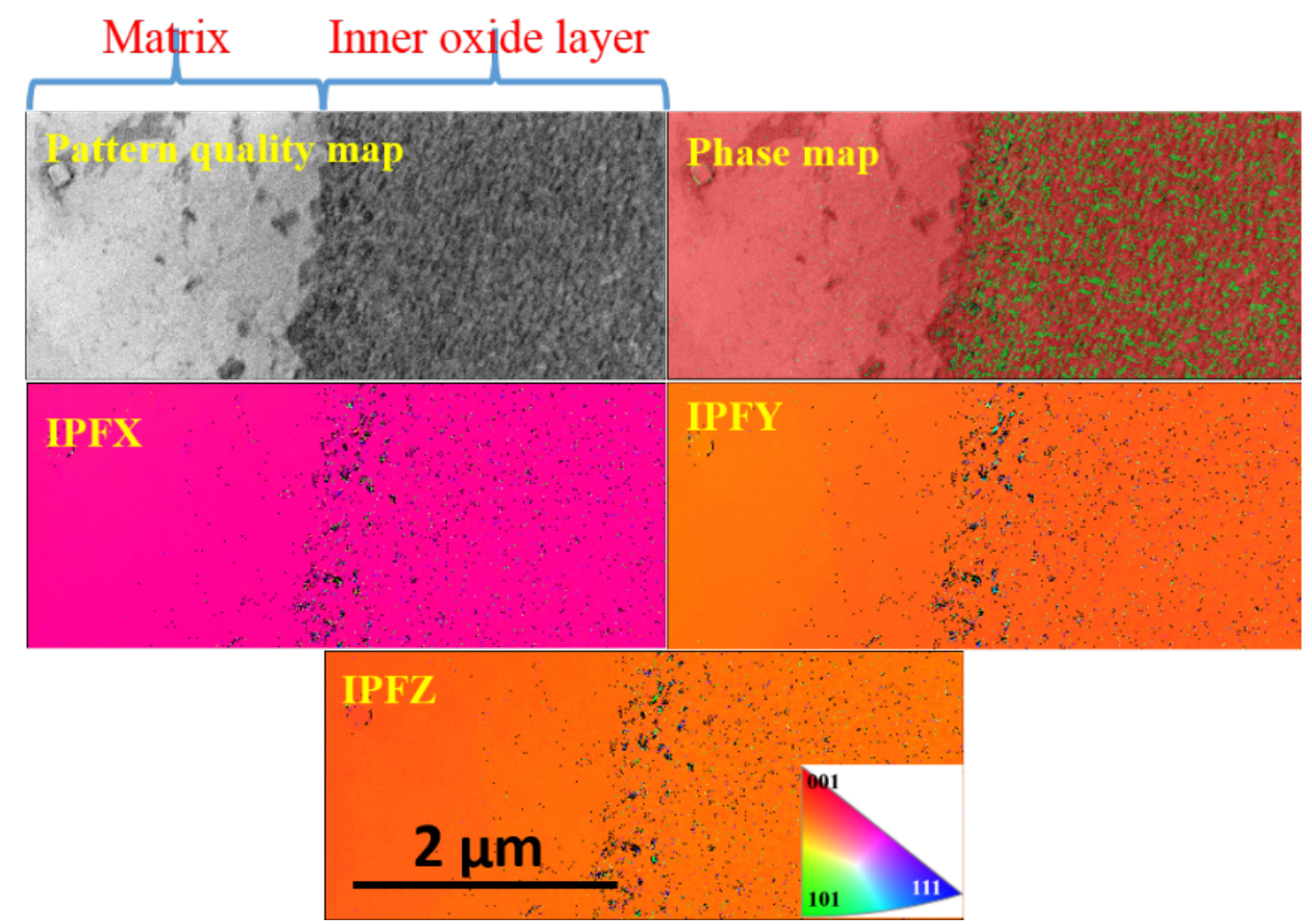

(a)

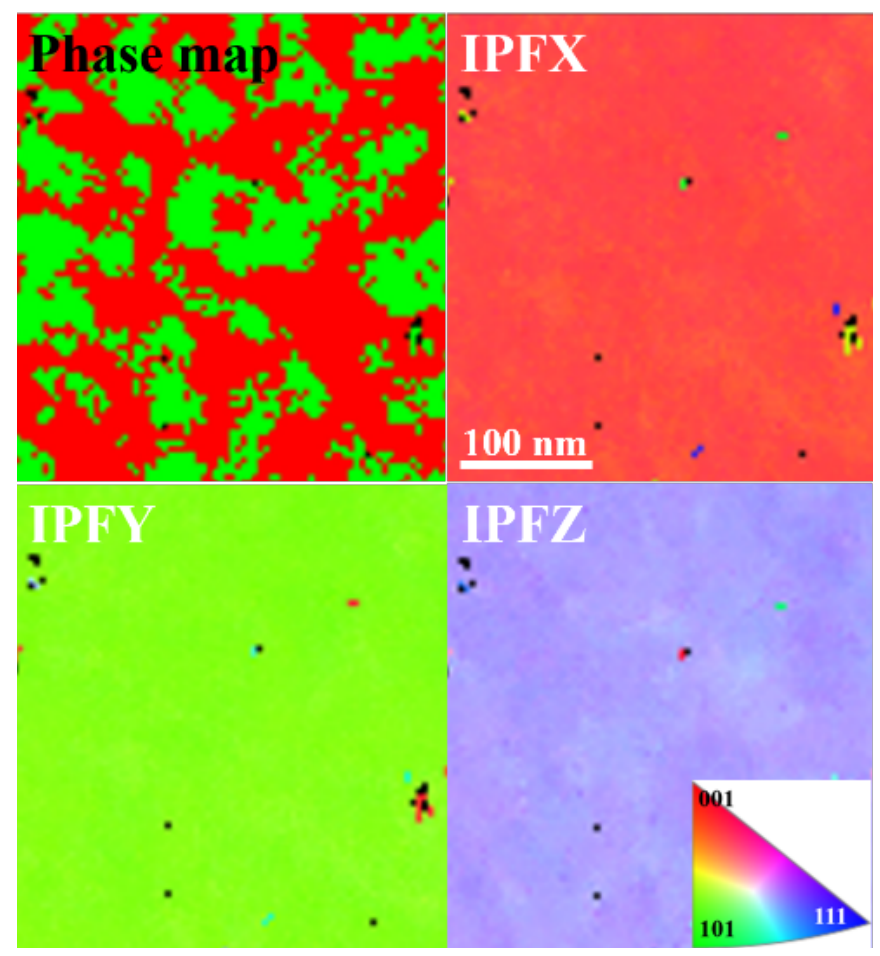

(b)

Fig. 7. (a) TKD analysis (step size $=10 \mathrm{~nm}$ ) on TEM sample 1 showing the pattern quality map (top left), phase map (austenite phase in red and spinel oxide phase in green, top right), IPFX map (middle left), IPFY (middle right), and IPFZ (bottom); (b) TKD analysis on TEM sample 2 ( step size $=3 \mathrm{~nm}$ ) showing the phase map (austenite phase in red and spinel phase in green, top left), IPFX map (top right), IPFY (bottom left), and IPFZ (bottom right). 


\section{Inner oxide layer Matrix}

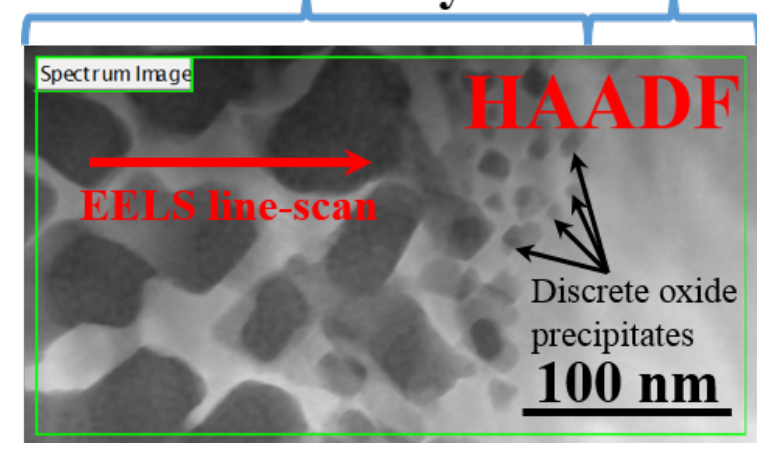

(a)

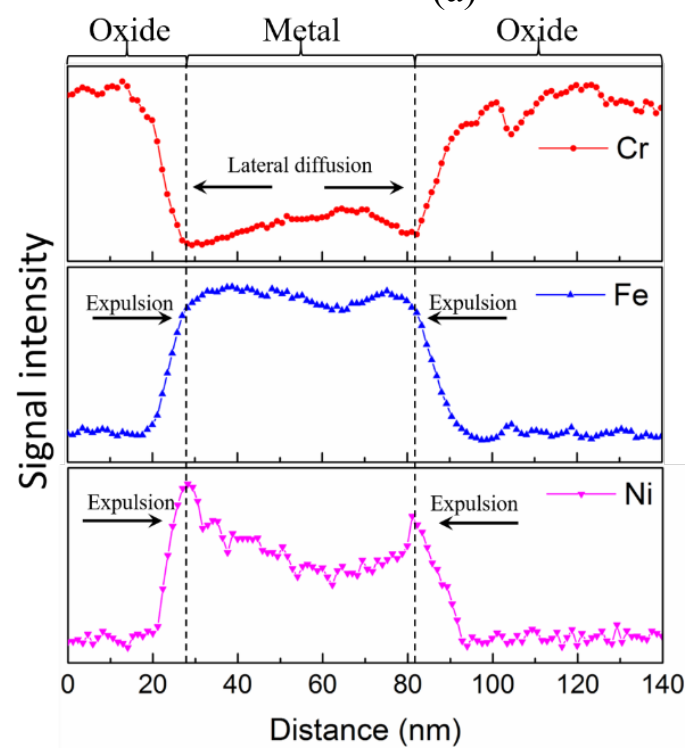

(c)

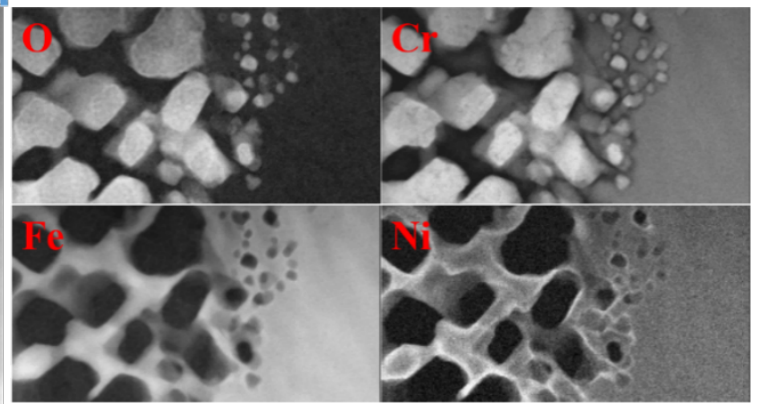

(b)

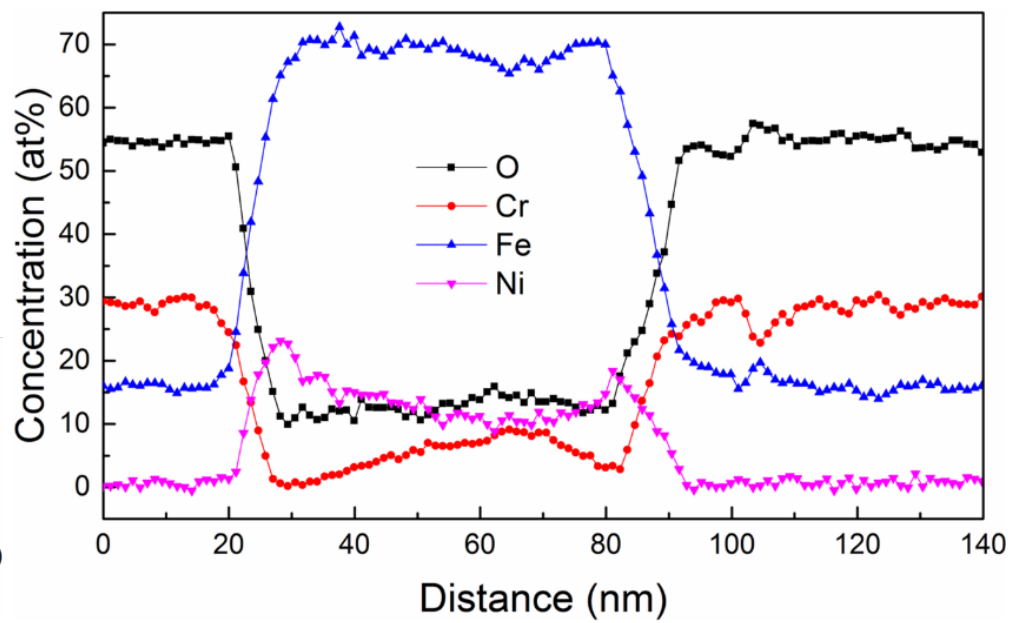

(d)

Fig. 8. Morphology and chemistry of the two-phase structure in TEM sample 1. (a) HAADF image showing the morphology around the inner oxide layer-metal matrix interface (TEM sample 1); (b) qualitative and EELS chemical composition maps showing the distribution of $\mathrm{O}, \mathrm{Cr}, \mathrm{Fe}$, and $\mathrm{Ni}$; (c) qualitative and (d) quantitative EELS chemical composition line-scan showing the distribution of $\mathrm{O}$, $\mathrm{Cr}, \mathrm{Fe}$, and Ni. 




(a)

(b)

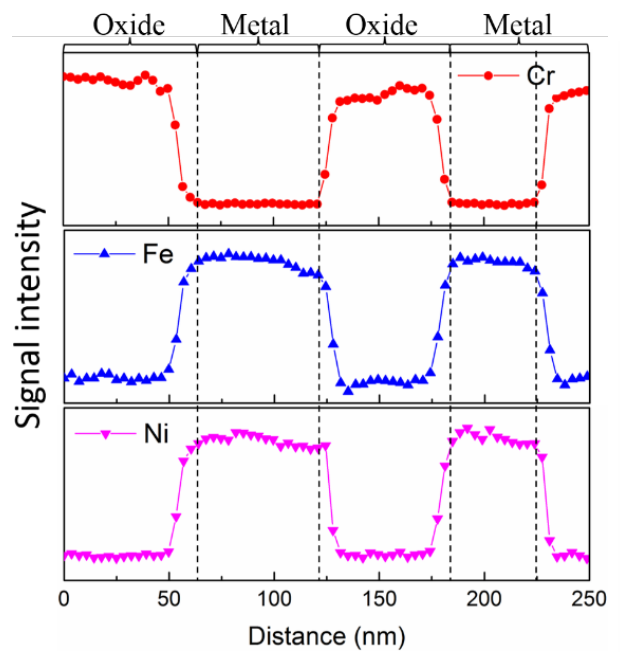

(c)

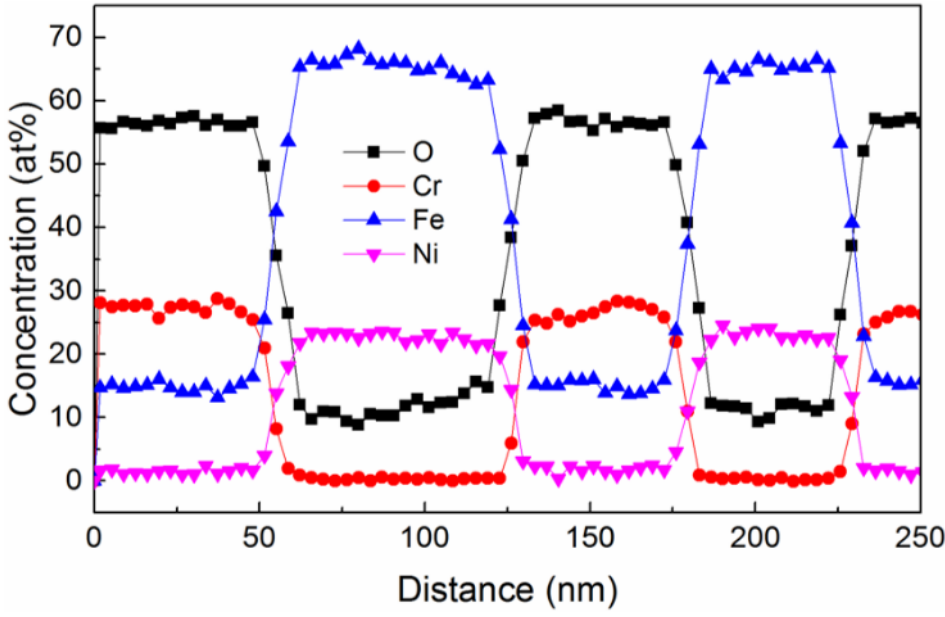

(d)

Fig. 9. Morphology and chemistry of the two-phase structure in TEM sample 2. (a) HAADF image showing the morphology of the inner oxide layer (TEM sample 2); (b) EELS qualitative chemical composition maps showing the distribution of $\mathrm{O}, \mathrm{Cr}, \mathrm{Fe}$, and $\mathrm{Ni}$; (c) qualitative and (d) quantitative EELS chemical composition line-scan showing the distribution of $\mathrm{O}, \mathrm{Cr}, \mathrm{Fe}$, and $\mathrm{Ni}$. 


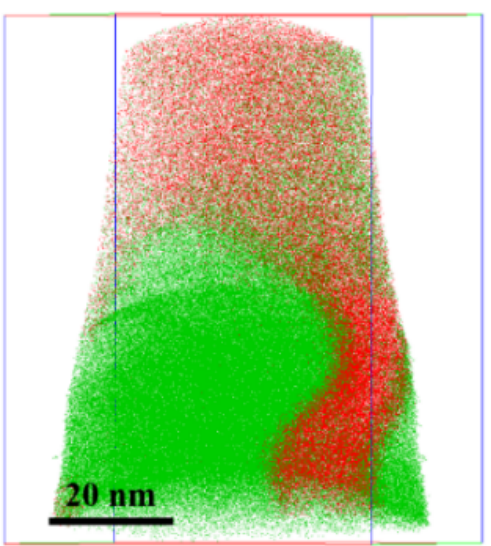

(a)
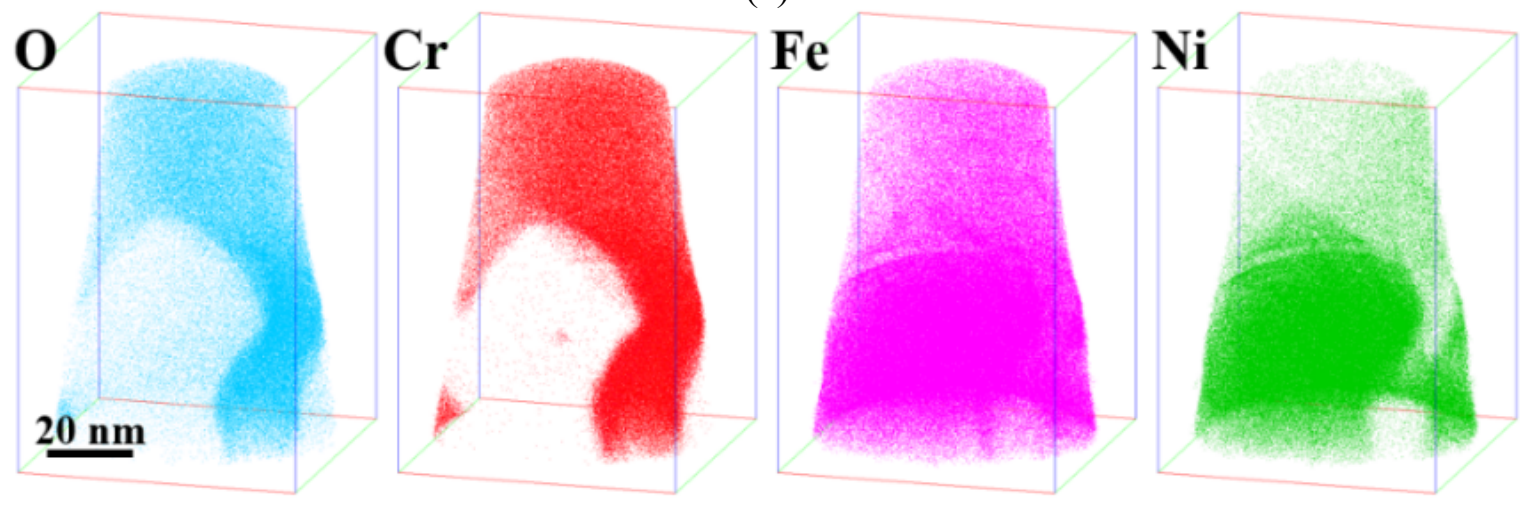

(b)
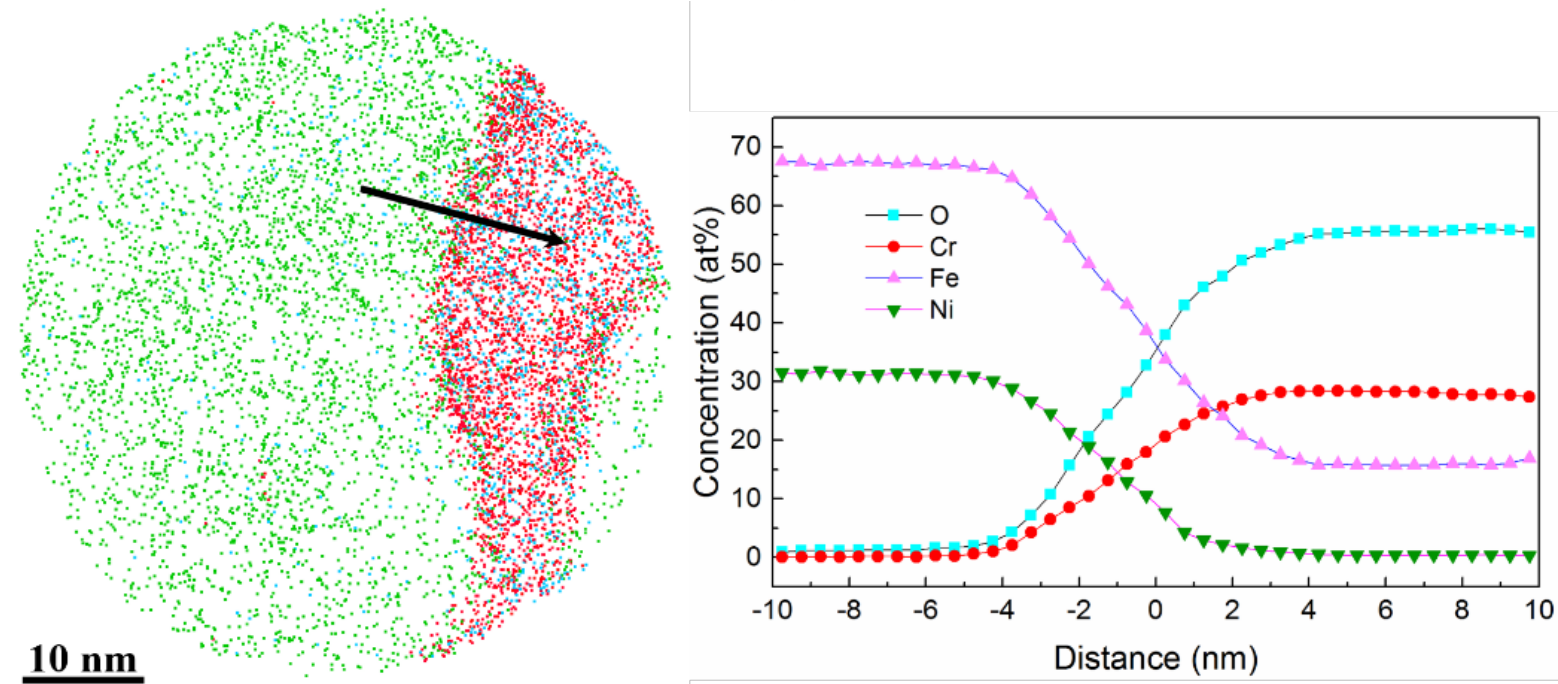

(c)

Fig. 10. (a) APT data set showing the $3 \mathrm{D}$ distribution of the two phases in the inner oxide layer $(\mathrm{Cr}$ in red and $\mathrm{Ni}$ in green); (b) spatial distribution of $\mathrm{O}, \mathrm{Cr}, \mathrm{Fe}$, and $\mathrm{Ni}$ in separate data sets; (c) concentration profiles across the oxide-metal phases interface. 


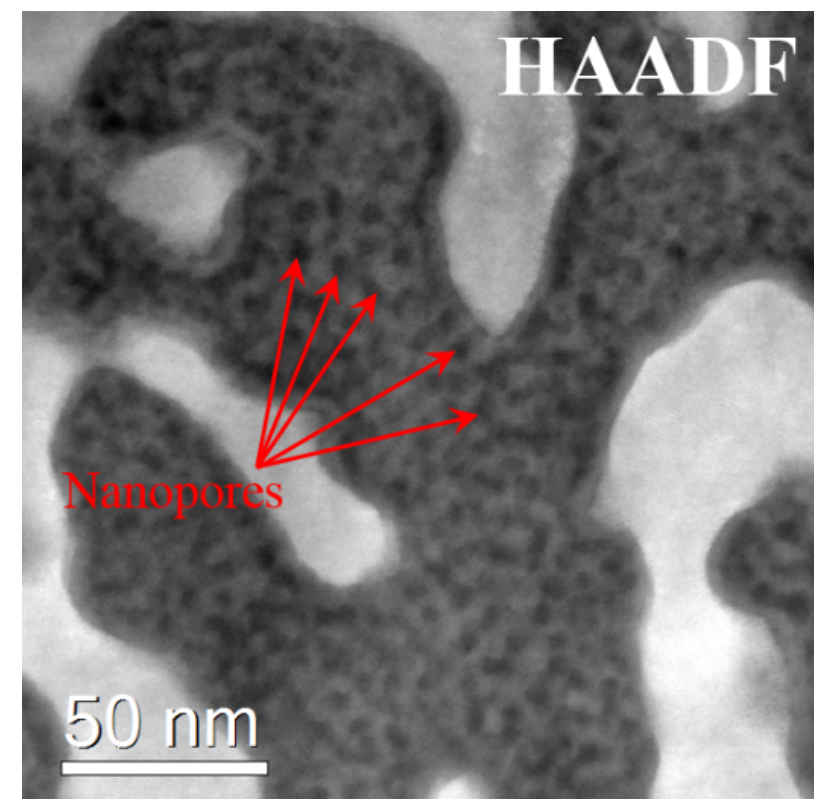

(a)

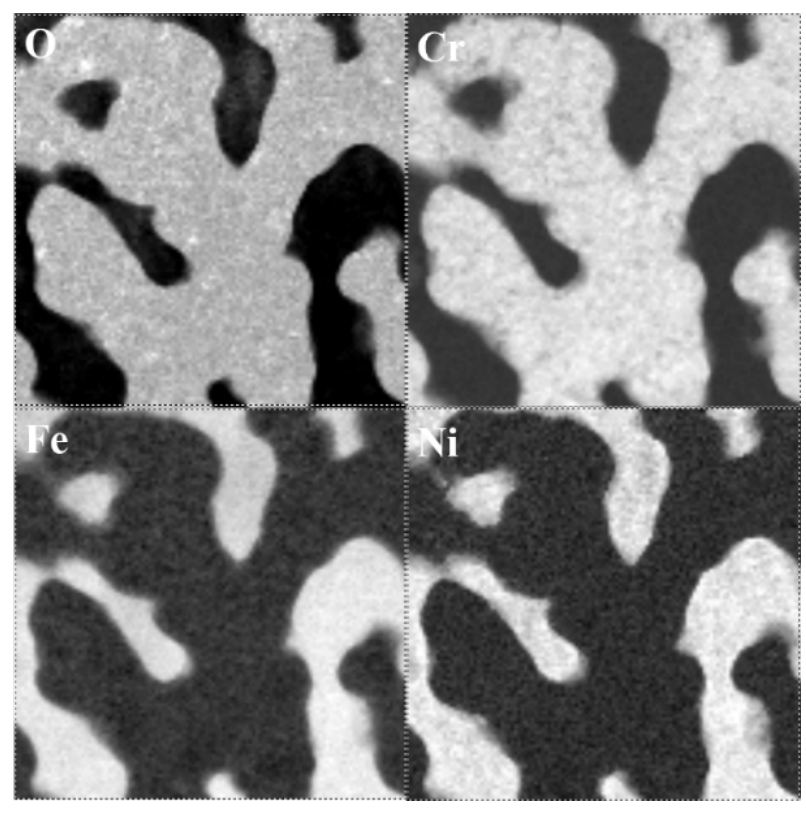

(b)

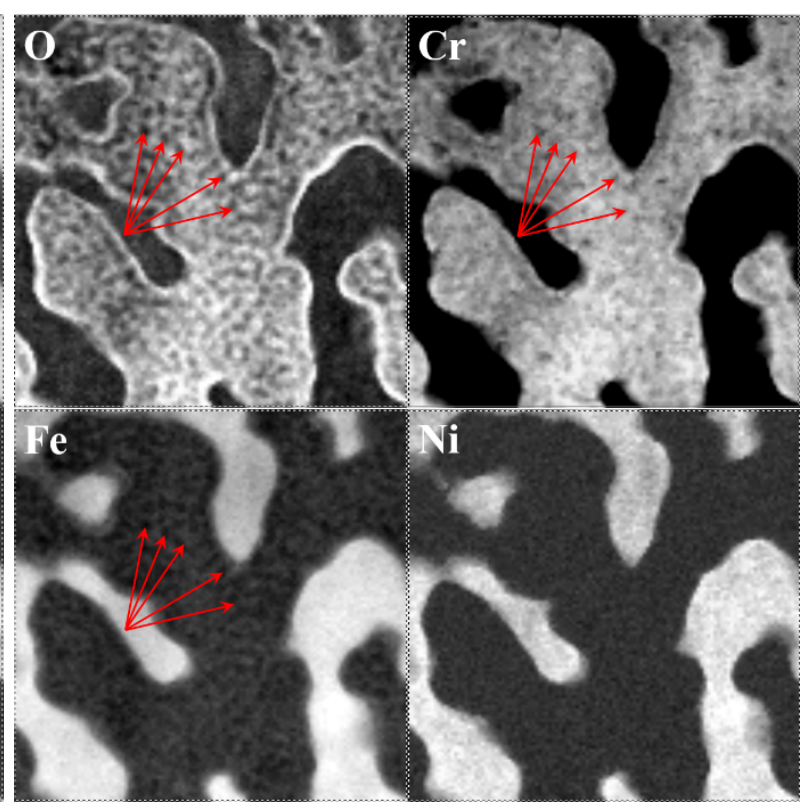

(c)

Fig. 11. Nanoporosity in the oxide phase. (a) HAADF image showing the two-phase structure of the inner oxide layer (TEM sample 2); (b) quantitative and (c) qualitative EELS chemical composition maps showing the distribution of $\mathrm{O}, \mathrm{Cr}, \mathrm{Fe}$, and $\mathrm{Ni}$. 


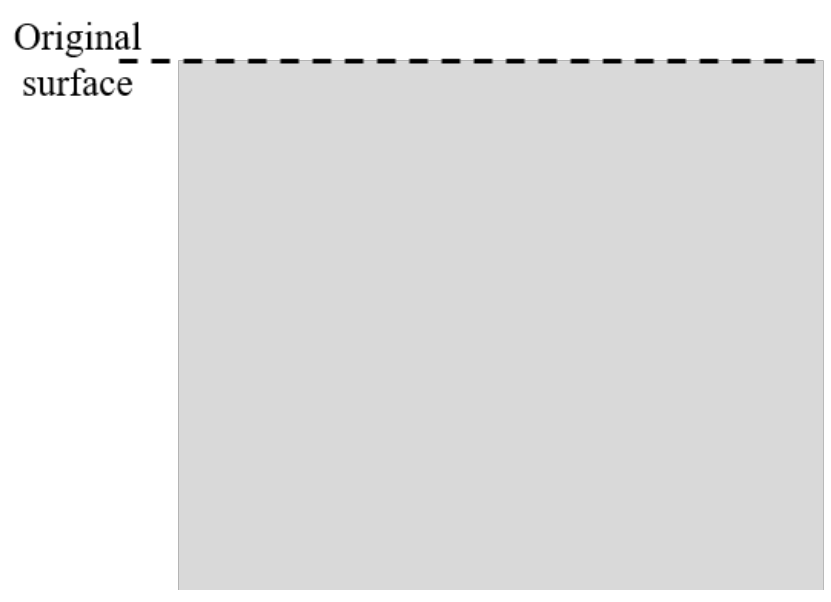

(a)

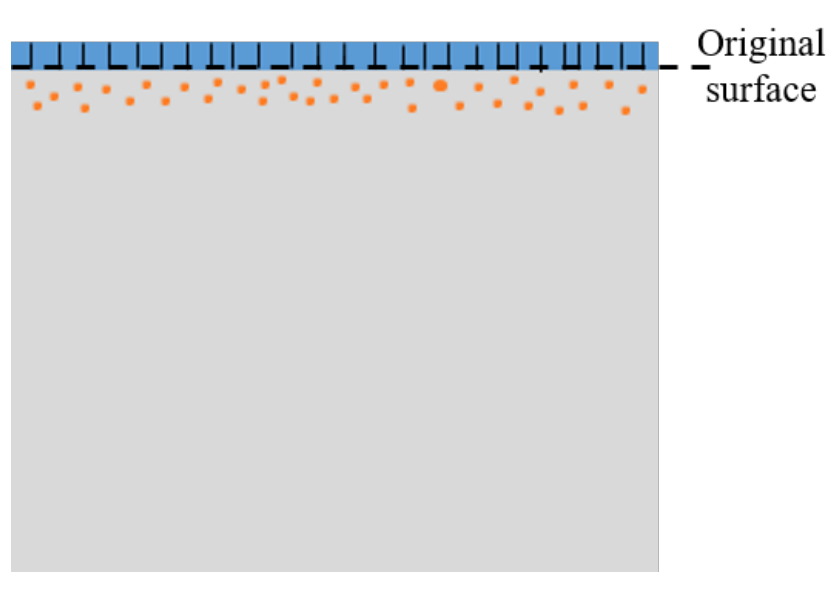

(b)

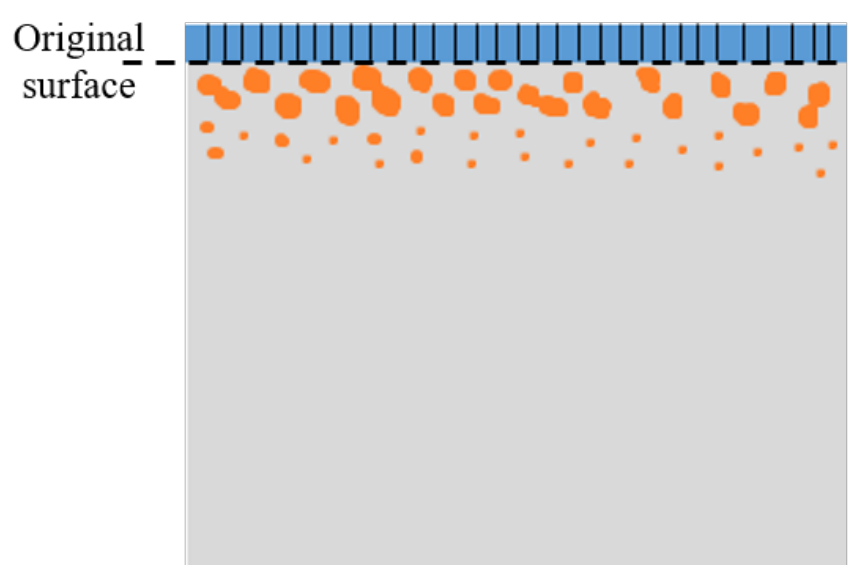

(c)

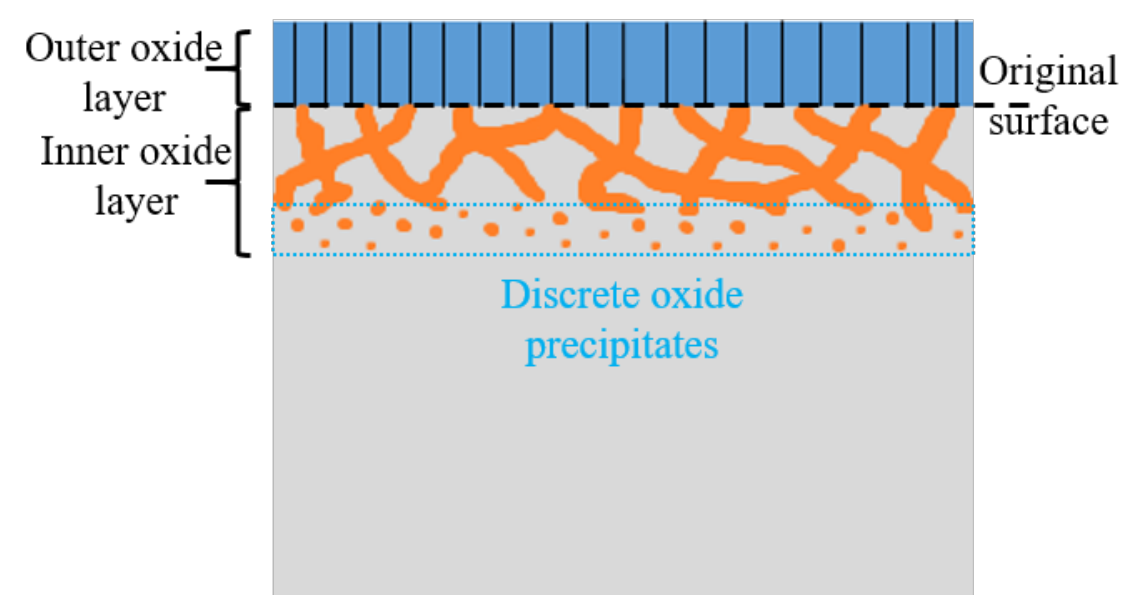

(d)

Fig. 12. Schematic illustration of the process of high-temperature oxidation of Fe-17Cr-9Ni SS in steam at $600^{\circ} \mathrm{C}$ (a-d). 